Bundesgesundheitsbl 2020 -63:1025-1053 https://doi.org/10.1007/s00103-020-03183-y c) Springer-Verlag GmbH Deutschland, ein Teil von Springer Nature 2020

Wissenschaftliche Erläuterungen zur TRIM-Stellungnahme

\title{
Wissenschaftliche Erläuterungen zur Stellungnahme Transfusionsassoziierte Immunmodulation (TRIM) des Arbeitskreises Blut vom 13. Februar 2020
}

\section{Bei der 88. Sitzung des Arbeitskreises Blut am 13. Februar 2020 wurde folgende Ergänzung zu Stellungnahme (S 22) verabschiedet}

beispielsweise proinflammatorische Effekte durch freigesetzte Zytokine von allogenen Monozyten und T-Zellen und immunsuppressive Effekte durch Zytokine von Neutrophilen nach Kontakt mit allogenen EK-Überständen [5-7]. Auch die Induktion von regulatorischen T-Zellen mit potentiellem Einfluss auf Tumorwachstum und Infektabwehr wurde nach Kontakt mit allogenen EK-Überständen beobachtet [8]. Einige Effekte werden abhängig von der Lagerung und dem Zeitpunkt der Leukozytendepletion (vor oder nach Lagerung) verstärkt, andere scheinen lagerungsunabhängig zu sein (z. B. Induktion regulatorischer T-Zellen) [7]. Auch die Adhäsion von transfundierten Erythrozyten an das Gefäßendothel und eine dadurch angestoßene Endothelzell-Aktivierung mit Auswirkungen auf das Gerinnungssystem werden zum Verständnis von TRIM-Effekten herangezogen $[9,10]$. Weitgehend unklar ist bisher der Einfluss einer vorbestehenden krankheitsbedingten Immundysregulation bei Personen, die EK erhalten, sowie die Relevanz der Transfusion von Früh- und Reifgeborenen mit Erythrozyten eines Erwachsenen für die mögliche zusätzliche Beeinflussung des Immunsystems durch EK-Transfusionen [11].
Die Diskussion um mögliche klinisch relevante, negative Auswirkungen von Transfusionen auf das Immunsystem wurde auch in der Laienpresse aufgegriffen (Die rote Gefahr, Stern 12.02.2017; Dokumentation „Böses Blut - Transfusionsrisiken, Kehrtwende in der Intensivmedizin“, ARD 24.11.2014; „Wenn das Blut uns krank macht“, odysso - Wissen im SWR, SWR Fernsehen 08.06.2017) und verunsicherte sowohl Patientinnen und Patienten als auch Ärztinnen und Ärzte.

In dieser Stellungnahme bewertet der Arbeitskreis Blut die vorhandenen Daten $\mathrm{zu}$ immunmodulatorischen Effekten von leukozytendepletierten EK hinsichtlich der Assoziation mit Infektionen und Krebserkrankungen. Aufgrund der Komplexität der Fragestellung und Bewertung wird eine methodische Erläuterung vorangestellt.

\section{Bewertung der Fragestellung - methodischer Prolog}

\subsection{Studientypen}

Randomisierte kontrollierte Studien (RCT) gelten aus erkenntnistheoretischer Sicht als Goldstandard der klinischen Forschung. Ihnen wird der höchste Evikrankung begünstigen könnte, sind bis dato nicht bekannt. Diskutiert werden 
denzgrad bei der Erstellung von Therapieempfehlungen zugeschrieben [12]. Die zufällige Zuordnung von Patienten zu einer Interventionsgruppe führt dabei mit hoher Wahrscheinlichkeit zu einer Strukturgleichheit der Patientengruppen und ermöglicht einen direkten Vergleich von Therapieeffekten - sofern im Studienverlauf keine weiteren Verzerrungen auftreten [13].

Um die Randomisierung aus einer möglichst homogenen Basispopulation zu gewährleisten, gelten für die Patienten meist sehr spezifische Einschluss- bzw. Ausschlusskriterien bezüglich demografischer Merkmale, Krankheitsschwere, Komorbiditäten etc.. Die Erkenntnisse aus RCTs sind durch eine hohe interne Validität gekennzeichnet, lassen sich jedoch wegen der selektionierten Patientenkollektive mit speziellen Eigenschaften und den zum Teil künstlichen Studienbedingungen nur bedingt auf andere Patientengruppen übertragen.

Allerdings sind auch RCTs nicht frei von möglichen Verzerrungen. Beispielsweise kann eine unverblindete Zuordnung der Patienten zu einer der Therapiegruppen die (unverblindete) Erhebung des Outcome mitunter erheblich beeinflussen und Studienergebnisse (Effektschätzer) verzerren $[14,15]$. Kritisch hinterfragt werden sollte auch eine Datenanalyse per protocol, bei der nur jene Patienten eingeschlossen werden, die tatsächlich auch die zugeloste Therapie erhalten haben, was zu einer Aufhebung der durch die Randomisierung ermöglichten Gleichverteilung von Risikofaktoren in den Therapiearmen führen kann [16].

Neben den primären Endpunkten, auf die eine Intervention abzielt und untersucht wird, wird in RCTs regelmäßig auch die Auswirkung der Intervention auf weitere klinisch oder Public Healthrelevante (sekundäre) Endpunkte analysiert. Häufig publiziert werden auch post hoc-Subgruppenanalysen zur Überprüfung der Auswirkung von Interventionen in Patientengruppen mit bestimmten (Baseline-)Eigenschaften. Sowohl bei der Analyse von multiplen sekundären Endpunkten als auch bei Subgruppenanalysen besteht die Gefahr, dass die Wahrscheinlichkeit für falsche Rückschlüsse durch Akkumulation von $\alpha$-Fehlern beim multiplen Testen steigt. Andererseits ist die Power der Studien in der Regel für die Betrachtung des primären Endpunktes in der gesamten Studienpopulation ausgelegt, so dass die Power für den statistischen Nachweis von Unterschieden bei sekundären Endpunkten bzw. in Subgruppen eventuell nicht ausreicht $[17,18]$. Ohne Berücksichtigung dieser Limitationen (z.B. durch statistische Tests auf Interaktionen bei Subgruppenanalysen [18, 19]) sind die Ergebnisse solcher Analysen nicht verwertbar oder sogar falsch, wie die Autoren der ISIS-2-Studie am Beispiel von Patientengruppen mit verschiedenen Sternzeichen zeigen konnten [20].

Bei der Interpretation von Studienergebnissen sollte beachtet werden, dass in publizierten randomisierten Studien einige Outcome-Parameter oftmals unvollständig oder nicht berichtet werden. Nebenwirkungsereignisse sind davon offenbar häufiger betroffen als Parameter für die Wirksamkeit einer Intervention [21].

Ergebnisse aus (nicht-randomisierten) Beobachtungsstudien, z. B. Kohortenstudien oder Fall-Kontroll-Studien, werden in der Regel mit einem geringeren Evidenzgrad bewertet, da sie anfälliger sind für systematische Fehler (Bias) und den Einfluss von Störgrößen, die sowohl mit der Exposition als auch mit dem Outcome assoziiert sind (Confounder). Sind mögliche Confounder im Vorhinein nicht bekannt oder werden sie aus anderen Gründen nicht valide und vollständig erfasst, können die Studienergebnisse erheblich verzerrt sein. Eine statistische Korrelation (zwischen Exposition und Outcome) würde in diesem Fall einen kausalen Zusammenhang lediglich vortäuschen. Grundsätzlich muss bei der Interpretation und Bewertung von retrospektiven Analysen oder prospektiven, nicht randomisierten Beobachtungsstudien beachtet werden, dass keine Kausalität, sondern allenfalls eine statistische Assoziation zwischen Exposition (z.B. EK-Transfusion) und Outcome (z.B. Pneumonierate) beschrieben werden kann.

Ein insbesondere in der klinischen Forschung $\mathrm{zu}$ beachtendes Phänomen ist das sogenannte „confounding by indication“ (oder „indication bias“). Dies tritt auf, wenn die klinische Indikation für eine bestimmte Therapie auch Einfluss auf das Behandlungsergebnis hat. Beispielsweise erhalten Patienten mit schwereren Krankheitsverläufen und somit schlechteren Prognosen zumeist intensivere Therapien als Patienten mit leichten Erkrankungen. Die intensiven Therapiemaßnahmen sind deshalb häufig statistisch mit einem schlechteren Outcome assoziiert und scheinen weniger gut für die Behandlung geeignet zu sein als die Vergleichstherapien [22].

Durch Vermeidung systematischer Verzerrungen bei der Studiendurchführung und die Berücksichtigung von Confoundern bei der Analyse der Studiendaten können jedoch auch Beobachtungsstudien ähnlich valide Ergebnisse liefern wie RCTs. Beobachtungsstudien bilden meist das klinische, nicht-experimentelle Therapieprozedere besser ab und schließen häufig eine hinsichtlich demografischer und klinischer Charakteristika diverse Patientenpopulation ein. Die Repräsentativität solcher Studienpopulationen ist oft höher als die der Patienten in RCTs. Außerdem können Beobachtungsstudien für bestimmte Fragestellungen, für die RCTs nicht geeignet oder nicht durchführbar sind, valide Ergebnisse liefern. Dies ist beispielsweise der Fall bei der Untersuchung seltener Nebenwirkungen oder Spätfolgen von Medikamenten bzw. Therapien.

Generell zeigt sich bei identischen Studienfragen eine weitgehende Kongruenz zwischen den Ergebnissen von RCTs und gut konzipierten Beobachtungsstudien [23]. Mitunter weichen die Ergebnisse aber deutlich voneinander ab, wobei sowohl RCTs als auch nicht-randomisierte Studien größere Therapieeffekte beobachteten [24]. Die Beurteilung von Therapiemaßnahmen soll deshalb immer auf der Bewertung mehrerer unabhängiger Studien beruhen [25].

$\mathrm{Zu}$ diesem Zweck werden zunehmend Metaanalysen bzw. systematische Reviews erstellt, die die Ergebnisse aus verschiedenen Studien zur gleichen Fragestellung zusammenfassend beschreiben (systematischer Review) bzw. gepoolt auswerten (Metaanalysen). Metaanalysen wird ein hoher Evidenzgrad zugeschrieben - wenngleich die Methodik [26, 27] und die Validität der gepoolten Ergebnis- 
se $[28,29]$ auch kritisch diskutiert werden. Um wichtige - für die methodische Qualität entscheidende - Aspekte bei systematischen Reviews und Metaanalysen $\mathrm{zu}$ berücksichtigen, wurden in den letzten 25 Jahren methodische Standards etabliert und weiterentwickelt $[30,31]$. Systematisch zu prüfende Punkte sind vor allem das Ausmaß von Fehlern (Bias) bei der Identifikation geeigneter Primärstudien (publication bias, search bias, selection bias), die Verfügbarkeit von Patientendaten, die Bewertung der Ergebnisheterogenität sowie die Datenanalyse (Meta-Regression) $[32,33]$.

Die zunehmende Publikation solcher Arbeiten, die nicht immer den oben genannten Qualitätsstandards entsprechen [34], erfordert eine entsprechende Sorgfalt bei der Interpretation von Ergebnissen aus Metaanalysen. Die oben genannten Kriterien sollten deshalb nicht nur beim Erstellen von Metaanalysen sondern auch beim Lesen geprüft werden. $\mathrm{Zu}$ beachten ist insbesondere, dass Metaanalysen mitunter nicht repräsentativ für die Gesamtheit der existierenden Studien sind. So ist die Publikation von klinischen Studien mit signifikanten Therapieunterschieden um einiges wahrscheinlicher als von Studien, die keine Unterschiede zwischen den Interventionen fanden [35]. Häufig basieren Metaanalysen auch ausschließlich auf Studien mit unzureichender Power, wie eine Analyse von ca. 2000 Cochrane Reviews zeigt [36]. Die Ergebnisse von Metaanalysen sollten deshalb unter Berücksichtigung einer Heterogenitätsanalyse der Einzelstudien interpretiert werden [37].

Metaanalysen spielen bei der Kausalitätsbewertung von Zusammenhängen eine wichtige Rolle, reichen aber nicht aus, um Kausalität zu belegen. Sie können auf Basis statistischer Verfahren die Prüfung der Konsistenz von Studien unterstützen und Schätzungen für die Stärke von $\mathrm{Zu}$ sammenhängen und das Ausmaß einer Dosis-Wirkungsbeziehung liefern [38]. Darüber hinaus sollte in die Bewertung eines möglichen kausalen Zusammenhanges die Prüfung weiterer Kriterien, z. B. der sogenannten Bradford-Hill-Kriterien (biologische Plausibilität, Spezifität der Assoziation, Reproduzierbarkeit u.a.), einfließen [39].

\subsection{Besonderheiten von Studien zu unerwünschten Nebenwirkungen von Bluttransfusionen}

Anders als bei klassischen pharmakologischen Studien untersuchen Studien zu Bluttransfusionen die Auswirkungen/Effekte naturgemäß heterogener Blutprodukte. Auch wenn die Herstellung von Blutkomponenten streng reguliert ist und industriellen pharmazeutischen Standards sehr nahe kommt, zeichnen sich diese Blutprodukte durch individuelle Eigenschaften aus, die einerseits durch Spendercharakteristika bestimmt werden, andererseits aber auch maßgeblich von Produktions- und Lagerungsprozessen abhängen [40]. Unerwünschte Transfusionsreaktionen, die aus dem Vorhandensein bestimmter Produkteigenschaften resultieren, werden - solange diese Eigenschaften im Dunkeln liegen bzw. in den Studien nicht separat untersucht werden - generell dem Transfusionsereignis zugeordnet. Die überwiegende Anzahl von Studien zu Transfusionsnebenwirkungen, die eine durch die EK-Transfusion ausgelöste TRIM nahelegen, berücksichtigt spezifische Produkteigenschaften (bisher) nicht.

Des Weiteren ist zu beachten, dass eine präoperativ vorliegende Anämie eine Ursache für die Indikation perioperativer EK-Transfusionen $[41,42]$ und gleichzeitig mit (postoperativer) Morbidität und Mortalität assoziiert ist und somit als unabhängiger Risikofaktor gilt. Sowohl in bevölkerungsbasierten Langzeitkohorten als auch in klinischen Settings mit nichttransfundierten Patientenkohorten wurde gezeigt, dass eine prävalente Anämie die Mortalitäts- und Morbiditätsprognose signifikant verschlechtert [41, 43-45]. Dieser Zusammenhang ist bei der Bewertung von Studien (Design, Datenanalyse, Ergebnisse) zur Auswirkung von EK-Transfusionen zu berücksichtigen.

\subsubsection{Randomisierte klinische Studien}

1. Die meisten randomisierten Studien in der Transfusionsmedizin zielen auf die Bewertung der Sicherheit bzw. auf die Prüfung der Nichtunterlegenheit verschiedener Transfusionsstrategien ab. Dazu werden die Outcomes von EK-Transfusionen bei niedrigem Grenzwert der Hämoglobinkonzentration (restriktive Transfusionsstrategie) mit den Outcomes von Transfusionen bei höheren Hämoglobinkonzentrationen (liberale Transfusionsstrategie) verglichen [46]. Obwohl solche Studien nicht primär auf das Auftreten von TRIM abzielen, werden sie vielfach dazu herangezogen. Die erhobenen Outcomes werden dabei mit der Tatsache in Beziehung gesetzt, dass bei liberaler Transfusionsstrategie im Allgemeinen EK häufiger transfundiert werden bzw. mehr EK-Volumen eingesetzt wird als bei restriktiver Transfusionsgrenze. Allerdings lassen sich auf diesem Wege trotz Randomisierung die beobachteten Effekte nicht direkt auf eine Exposition gegenüber Blutprodukten zurückführen, da 1. in der Regel keine Vergleichspopulation ohne EK-Transfusionen vorliegt und 2. die Patienten in den Therapiegruppen nach unterschiedlichen Protokollen (liberal vs. restriktiv) transfundiert wurden. Es kann dabei nicht ausgeschlossen werden, dass sich Transfusionseffekte und Auswirkungen von Anämien mit unterschiedlichem Schweregrad überlagern. Randomisierte Studien mit identischem Transfusionsgrenzwert in den Interventionsarmen und verschiedenen Transfusionszielen (z. B. unterschiedliche Hb-Werte) wären für die direkte Untersuchung TRIM-spezifischer Effekte besonders geeignet.

2. Bei randomisierten Studien zu verschiedenen Transfusionsstrategien hat das Klinikpersonal in der Regel Kenntnis von der zugelosten Therapie (fehlende Verblindung). Auch die Erhebung der verschiedenen Studienoutcomes erfolgt häufig unverblindet [46]. Dies sollte bei der Bewertung von Studienergebnissen berücksichtigt werden, insbesondere wenn die Möglichkeit/Gefahr besteht, dass die Patienten im Nachgang der Transfusionen unterschiedlich behandelt werden (performance bias). Die Erhebung einiger Endpunkte wie beispielsweise die Gesamtmortalität wird allerdings 
kaum von einer fehlenden Verblindung beeinflusst.

3. Ein Großteil der Studien schließt nur eine relativ kleine Zahl von Patienten ein. Hier ist empfehlenswert, vor allem Studien mit einer intention to treat-Analyse für die Bewertung heranzuziehen. Bei Studien mit niedriger Fallzahl ist die Gefahr einer Verzerrung durch Ausschluss von Patienten wegen Nichteinhaltung des Therapieplans mitunter sehr groß.

4. Aufgrund der Vielzahl an möglichen patienten- und behandlungsrelevanten Folgen von Operationen, die durch Transfusionen beeinflusst werden können, wurden in den RCTs mit verschiedenen Transfusionsstrategien häufig >10 sekundäre Endpunkte definiert. Die sich aus multiplen Signifikanztests ergebenden Limitationen sollten bei der Interpretation der Ergebnisse berücksichtigt werden - ebenso wie die Tatsache, dass die Studiengröße/Power für eine valide Betrachtung sekundärer Endpunkte und für andere post hoc-Analysen mitunter nicht ausreicht (vgl. $[47,48])$.

\subsubsection{Beobachtungsstudien}

1. Im Gegensatz zu den randomisierten klinischen Studien lässt sich in Beobachtungstudien ein Vergleich von Outcomes bei Patienten ohne Transfusion und Patienten mit Transfusion(en) realisieren. In der Vergangenheit wurden vor allem retrospektive Kohortenstudien zur Untersuchung möglicher TRIM-assoziierter Auswirkungen durchgeführt. Kohortenstudien haben ein geeignetes Design, um das Auftreten sogenannter "unintended effects“ (Nebenwirkungen) zu untersuchen [49]. Untersuchungen zur Gesamtmortalität und -morbidität nach Bluttransfusion können bei Kohortenstudien allerdings kritisch sein, da bei diesen Outcomes ein „indication bias“ („confoundig by indication“, s. unten) meist nicht ausgeschlossen werden kann.

2. Confounding by indication in einer Beobachtungsstudie kann nur vermieden werden, wenn die zu er- hebenden Outcomes nicht mit der Indikation für die Transfusion assoziiert sind. Dies kann nur in (wenigen) bestimmten Kohorten ausgeschlossen werden, in denen eine Transfusionsindikation nicht auf einer bereits bestehenden Anämie beruht bzw. davon beeinflusst wird. Für die Bewertung von möglichen negativen Effekten einer Transfusion im Sinne einer TRIM sollten in erster Linie Studien herangezogen werden, für die ein indication bias unwahrscheinlich ist.

3. Von entscheidender Bedeutung sind die Erhebung möglicher Confounder und deren Berücksichtigung bei der Analyse der Studiendaten. Dies kann entweder über die Adjustierung multivariabler Modelle mit den Confoundervariablen realisiert werden oder über die Zuordnung eines sogenannten propensity score zu allen Patienten [50, 51]. Ohne diese statistischen Verfahren ist eine möglichst verzerrungsfreie Berechnung von Effektschätzern in Populationen mit ungleichen Risikoprofilen nicht möglich.

Ein zentrales Problem bei den Beobachtungsstudien zu Transfusionsauswirkungen ist die bisher nahezu unberücksichtigte Behandlungsqualität (z. B. Qualifikation und Erfahrung der Chirurgen) als Confounder, der sowohl das Risiko für eine Transfusion als auch für sich anschlieBende Behandlungskomplikationen beeinflusst [52]. Die Mehrzahl der Beobachtungsstudien ist aus diesem Grund kaum geeignet, valide Effektschätzer für mögliche transfusionsassoziierte Nebenwirkungen zu liefern.

4. Den statistischen Modellen zur Berechnung möglicher Effekte von Transfusionen sollten kausale Modelle zugrunde liegen, die die strukturellen kausalen Beziehungen zwischen den Patienten- und Behandlungsvariablen sowie der Exposition und dem Outcome berücksichtigen [53]. Mit Hilfe solcher Modelle lassen sich a priori Faktoren (Variablen) identifizieren, die in dem häufig multifaktoriellen Wirkungsgefüge tatsächlich Confounder darstellen. Häufig er- folgt die Variablenselektion allerdings ausschließlich auf Basis statistischer Assoziationen von Kovariablen und Outcome. Nicht selten werden dadurch Mediator-Variablen (intermediates) oder non-Confounder in die Modelladjustierung eingeschlossen, was zu fehlerhaften Effektschätzern führt (overadjustment bias, unnecessary adjustment) [54].

\subsubsection{Metaanalysen}

Bei Metaanalysen ist die Prüfung auf einen möglichen Publikationsbias empfehlenswert. Ferner sollte überprüft werden, ob die Berechnung eines Gesamtschätzers auf Studien mit vergleichbaren Interventionen beruht. Beispielsweise erscheint eine gemeinsame Analyse von Studien mit der Fragestellung TRIM mit leukozytendepletierten und leukozytenhaltigen EK wenig sinnvoll. Auch große Unterschiede bei den Transfusionstriggern zwischen den jeweiligen RCTs sollten bei der Interpretation berücksichtigt werden. Es ist notwendig, die Einzelstudien gezielt zu analysieren. Dies ist bei den Studien zu Transfusionsnebenwirkungen besonders angeraten, wenn die RCTs nur sehr kleine Fallzahlen aufweisen.

Für die hier vorgelegte Stellungnahme zur TRIM wurden ausschließlich Studien bewertet, die leukozytendepletierte EK untersuchten, da die Leukozytendepletion seit 2001 in Deutschland vorgeschrieben ist und den Standard der klinischen Behandlung darstellt. Die Suche nach Studien erfolgte zum einen über medizinische Datenbanken unter Eingabe der relevanten Schlagworte, zum anderen über die in den systematischen Reviews eingeschlossenen Studien und den Bibliotheken der Autoren dieser Stellungnahme. 


\section{Der Einfluss der Transfusion von Erythrozytenkonzentraten auf Infektionen und das klinische Behandlungsergebnis in unterschiedlichen Patientengruppen}

\subsection{Erwachsene Patientinnen und Patienten}

In diesem Teil der Stellungnahme wurden die Studien hinsichtlich der Auswirkungen von Transfusionen bei unterschiedlichen Patientengruppen betrachtet. Dabei ist zu beachten, dass die Studien mit dem Ziel durchgeführt wurden, die Sicherheit verschiedener Transfusionsstrategien hinsichtlich klinisch relevanter Endpunkte zu bewerten oder als Machbarkeitsstudien konzipiert waren und nicht der Untersuchung einer möglichen TRIM dienten. Deshalb fokussiert die Analyse insbesondere auf Infektionen und postinfektiöse Komplikationen, die als Surrogatparameter für eine TRIM dienen könnten. Da auch andere klinische Endpunkte (insbesondere Mortalität) durch Organinfektionen oder (post)infektiöse Komplikationen verursacht sein können, wurden auch diese Endpunkte in die Betrachtung einbezogen.

In erster Linie wurden RCTs herangezogen, um die oben beschriebenen, durch das Studiendesign möglicherweise bedingten Verzerrungen zu begrenzen. Studien, in denen eine Patientengruppe nicht transfundiert (Placebo) und mit einer Transfusionsgruppe verglichen wird, sind aus medizinethischen Gründen nur schwer durchführbar. Nur zwei solche Studien mit dieser Fragestellung konnten identifiziert werden $[55,56]$. Daher wurden für die Bewertung in erster Linie Studien herangezogen, die zwei unterschiedliche Hb-Konzentration als Transfusionsgrenzwerte (,liberal“"vs. „restriktive“ Transfusionsstrategie) untersuchten. Dieser Ansatz ist auch insofern plausibel, als dass die Methodik die Entscheidungssituation des klinischen Alltags widerspiegelt („Bei welchem Hb-Wert transfundiere ich die Patientin bzw. den Patienten?"). In fast allen Studien mit diesem Design wurden Patientinnen und Patienten im liberalen Transfusionsarm erwartungsgemäß signifikant mehr transfundiert, so dass zumindest ein Dosisunterschied in der Transfusion hinsichtlich einer TRIM berücksichtigt werden kann.

Die vorliegenden RCTs wurden mit unterschiedlichen Patientengruppen (z. B. Patienten mit septischem Schock, Herzerkrankungen, Schädel-Hirn-Trauma, etc.) durchgeführt, bei denen von einer unterschiedlich starken Aktivierung des Immunsystems ausgegangen wird. Da der Einfluss des Immunstatus auf die mögliche Entwicklung einer TRIM bisher nicht geklärt und außerdem aus medizinischer Sicht relevant für das Outcome nach einer EK-Transfusion ist, wurden die Studien für die Bewertung nach unterschiedlichen Patientengruppen und Krankheitsentitäten systematisiert. Dies erlaubt, bei mehreren vorliegenden Studien zu einer Patientengruppe bzw. Krankheitsentität, die Ergebnisse miteinander $\mathrm{zu}$ vergleichen bzw. gemeinsam zu bewerten.

Im Folgenden werden die Ergebnisse für 10 Patientenkollektive dargestellt.

\subsubsection{Patienten nach orthopädischen Operationen (Hüft- oder Kniegelenksersatz, Hüftfrakturen)}

Insgesamt wurden 2500 Patienten in drei Studien untersucht (•Tab. 1).

$\mathrm{Zu}$ den möglichen Effekten unterschiedlicher Transfusionstrigger bei Patientengruppen, die sich orthopädisch-unfallchirurgischen Operationen unterzogen, wurden sieben Publikationen von drei Studien betrachtet. Primäres Studienziel war in allen Studien die Wiederherstellung der Mobilität. Als sekundäre Endpunkte oder im Rahmen von post hoc-Analysen wurden auch Unterschiede im Auftreten von Infektionen bzw. die Gesamtmortalität, Liegedauer oder andere Parametern bewertet. Zu beachten ist, dass die Randomisierung für einen bestimmten Transfusionstrigger in allen betrachteten Studien erst postoperativ erfolgte, so dass die Auswirkung einer prä- oder intraoperativen Transfusion unberücksichtigt bleibt. Dies ist insbesondere mit Blick auf Parameter, die mit einem deutlichen zeitlichen Abstand gemessen wurden, von Relevanz, da der Einfluss der nicht der Randomisierung unterliegenden prä- oder intraoperativ verabreich- ten Transfusionen nicht beurteilt werden kann.

Mit Blick auf Infektionen, die im VerlaufderStudie auftraten (Pneumonien und Wundinfektionen), wurden in den Studien (• Tab. 1) zwischen den Studiengruppen keine signifikanten Unterschiede gefunden. Dies betrifft auch andere Endpunkte wie den akuten Myokardinfarkt und die Schlaganfallrate.

Für die 30-Tage-Mortalität fanden alle drei Studien in der intention to treat-Analyse keinen Unterschied zwischen den Transfusionsstrategien. Lediglich in der per protocol-Analyse der TRIFE-Studie [61] war die 30-Tage-Mortalität bei liberal transfundierten Patienten signifikant niedriger.

Zwei weitere RCTs $[63,64]$ haben bei orthopädischen Patientinnen und Patienten Effekte von unterschiedlichen Transfusionsgrenzwerten untersucht. In diesen Studien unterschied sich allerdings weder die Anzahl transfundierter Personen noch die Menge an EK signifikant in den beiden Gruppen, so dass eine Auswertung der Studienergebnisse hinsichtlich einer TRIM nicht möglich ist.

\subsubsection{Onkologische Patienten}

$\mathrm{Zu}$ den möglichen Effekten unterschiedlicher Transfusionsgrenzwerte bei onkologischen Patientengruppen wurden fünf Studien mit insgesamt 653 Patienten betrachtet (• Tab. 2).

In keiner der Studien waren postoperative Infektionen als primärer Endpunkt definiert. Lediglich eine Studie [67] erfasste das Auftreten von Infektionen als sekundäres Outcome. In dieser Studie fand sich kein Unterschied zwischen liberaler und restriktiver Transfusionsgruppe hinsichtlich der Gesamtinzidenz von Infektionen. In 6 Unterkategorien infektiöser Komplikationen wurden keine Inzidenzunterschiede beobachtet. Lediglich abdominelle Infektionen traten in der restriktiven Gruppe signifikant häufiger auf.

Neben zwei Machbarkeitsstudien [65, 68] und einer Studie [66], die nach Einschluss von 6 Patienten wegen nicht-infektiöser Komplikationen in der liberal transfundierten Gruppe abgebrochen wurde, untersuchte eine Studie ein Composit-Outcome aus 30-Tage-Mortalität und/oder schweren klinischen Kompli- 
Tab. 1 Studiencharakteristika und Ergebnisse von RCT zu Auswirkungen von EK-Transfusionen bei Patienten nach orthopädischen Operationen

\begin{tabular}{|c|c|}
\hline Studie(n) & Carson 2011 [57] (+Carson 2015) [58] \\
\hline Patientenkollektiv & $\begin{array}{l}\text { Hüftfraktur } \\
n=2016\end{array}$ \\
\hline Studienziel & $\begin{array}{l}\text { Test der Hypothese, dass } \mathrm{Hb} \geq 10 \mathrm{~g} / \mathrm{dl} \text { funktionelle Wiederherstellung verbessert und Mortalität/Morbidität reduziert } \\
\text { Primäroutcome: Tod oder Unfähigkeit zum selbständigen Gehen nach } 60 \text { Tagen } \\
\text { Sekundäroutcome: Composite aus Tod, Myokardinfarkt und instabiler Angina pectoris } \\
\text { Tertiäroutcome: } 30-\text { Tage-Morbidität inkl. Pneumonie, Wundinfektion }\end{array}$ \\
\hline Transfusionstrigger & $\begin{array}{l}8 \mathrm{Hb} \text { vs. } 10 \mathrm{~g} / \mathrm{dl} \\
\text { postoperativ }\end{array}$ \\
\hline Ergebnisse & $\begin{array}{l}\text { Keine signifikanten Unterschiede: } \\
\text { Infektionen: Pneumonie, Wundinfektion } \\
\text { Tod, Mobilität, Entlassungszeitpunkt, Körperlicher Aktivitäts- oder Fatigue-Score (Carson 2011) } \\
\text { 3-Jahres-Mortalität, } \\
\text { Todesursachen (kardiovaskuläre Erkrankungen, Malignome, Schlaganfall, Demenz, Lungenerkrankung, andere oder unbekannte } \\
\text { Gründe), } \\
\text { Mortalität in der Subgruppe von Patienten mit Krebsanamnese (Carson 2015) }\end{array}$ \\
\hline Kommentar & $\begin{array}{l}\text { Signifikant häufigere Gründe für Transfusion in der restriktiven Gruppe: schneller Blutverlust, Herzinsuffizienz, Tachykardie oder } \\
\text { Hypotension } \\
\text { Randomisierung für liberale oder restriktive Transfusionsstrategie erst postoperativ. Prä- bzw. intraoperativ kein signifikanter } \\
\text { Unterschied in der Transfusionshäufigkeit in beiden Gruppen }\end{array}$ \\
\hline Studie(n) & Parker 2013 [59] \\
\hline Patientenkollektiv & $\begin{array}{l}\text { Hüftfraktur, } \geq 60 \text { Jahre und postoperativer } \mathrm{Hb} 8-9,5 \mathrm{~g} / \mathrm{dl} \\
n=200\end{array}$ \\
\hline Studienziel & $\begin{array}{l}\text { Non-inferior study für Transfusion bei Anämiesymptomatik } \\
\text { Primäroutcome: Mobilität }\end{array}$ \\
\hline Intervention & $\begin{array}{l}\text { Transfusion vs. Transfusion nur bei Anämiesymptomatik } \\
\text { postoperativ }\end{array}$ \\
\hline Ergebnisse & $\begin{array}{l}\text { Keine signifikanten Unterschiede: } \\
\text { Infektionen: Pneumonie, Clostridien-Diarrhö, Wundinfektion, Septikämie mit septischem Schock } \\
\text { Alle anderen Parameter bzw. Komplikationen (z. B. Mobilitätsscore, Liegezeit) }\end{array}$ \\
\hline Kommentar & Power für Mortalitätsanalyse nicht ausreichend \\
\hline Studie(n) & TRIFE (Gregersen 2015 [48, 60, 61], Blandfort 2017 [62]) \\
\hline Patientenkollektiv & $\begin{array}{l}\text { Hüftfraktur bei geriatrischen Patienten } \\
n=284\end{array}$ \\
\hline Studienziel & Physische Rehabilitation und Gesamtmortalität \\
\hline Transfusionstrigger & $9,7 \mathrm{Hb}$ vs. $11,3 \mathrm{~g} / \mathrm{dl}$ \\
\hline Ergebnisse & $\begin{array}{l}\text { Keine signifikanten Unterschiede: } \\
\text { Infektionen: Pneumonie, Harnwegsinfektionen, andere Infektionen } \\
\text { Signifikante Unterschiede: } \\
\text { In liberal transfundierter Gruppe: } \\
\text { Geringere Rate an Delir an Tag } 10 \\
\text { 30-Tage-Mortalität in per-protokoll-Analyse geringer (kein Mortalitätsunterschied bei intention-to-treat-Analyse) } \\
\text { Bessere Rehabilitation nach } 1 \text { Jahr (modifizierter Barthel-Index) }\end{array}$ \\
\hline Kommentar & $\begin{array}{l}\text { Keine Angaben zu Transfusionen vor postoperativer Randomisierung } \\
\text { Problem des multiplen Testens durch Auswertung zahlreicher (post-hoc-) Analysen } \\
\text { Analyse der Infektionsinzidenzen ohne ausreichende Power } \\
\text { Einschränkung der Interpretierbarkeit der 1-Jahres-Ergebnisse durch hohe Sterblichkeit in der Patientenkohorte }\end{array}$ \\
\hline
\end{tabular}

kationen als primären Endpunkt [67], eine weitere Studie [69] die 28-Tage Mortalität in beiden Gruppen. In diesen beiden Studien war die Sterblichkeit in der liberal transfundierten Gruppe signifikant niedriger - allerdings bei Bergamin et al.
[69] nur die 90-Tage-Mortalität. Die Studie von DeZern et al. [68], die Leukämiepatienten untersuchte, wies bei keinem Endpunkt, auch nicht bei Episoden neutropenischen Fiebers, das eventuell noch am ehesten als eine immunologisch verur- sachte Reaktion verstanden werden könnte, einen Unterschied zwischen den Studiengruppen auf.

Bei den Studien mit onkochirurgischen Patienten erfasste nur eine Studie postoperative Infektionen, die keinen Hinweis auf 


\section{Tab. 2 Studiencharakteristika und Ergebnisse von RCT zu Auswirkungen von EK-Transfusionen bei onkologischen Patienten}

\begin{tabular}{|c|c|}
\hline Studie(n) & Webert 2008 [65] \\
\hline Patientenkollektiv & $\begin{array}{l}\text { Akute Leukämie und Induktionschemotherapie oder Stammzelltransplantation } \\
n=60\end{array}$ \\
\hline Studienziel & $\begin{array}{l}\text { Machbarkeitsstudie für multizentrisches RCT } \\
\text { Überprüfung der Rekrutierungsstrategie und der Eignung des Transfusionskriteriums als Exposition, Dokumentation von Blutungen } \\
\text { Infektionen in Studie nicht untersucht }\end{array}$ \\
\hline Transfusionstrigger & $8 \mathrm{Hb}$ vs. $12 \mathrm{~g} / \mathrm{dl}$ \\
\hline Ergebnisse & $\begin{array}{l}\text { Keine signifikanten Unterschiede: } \\
\text { Mediane Zeit bis zur ersten Blutung bzw. bis zur ersten klinisch signifikanten Blutung } \\
\text { Häufigkeit klinisch signifikanter Blutungen }\end{array}$ \\
\hline Kommentar & $\begin{array}{l}\text { Kein Unterschied im Anteil der Personen mit EK-Transfusion } \\
\text { Signifikante Unterschiede nur bei EK-Menge und Transfusionen/Patiententag }\end{array}$ \\
\hline Studie(n) & Robitaille 2013 [66] \\
\hline Patientenkollektiv & $\begin{array}{l}\text { Kinder mit allogener Stammzelltransplantation } \\
n=6\end{array}$ \\
\hline Studienziel & Untersuchung der Auswirkungen eines höheren Hb-Triggers auf Normalisierung der Granulozyten-Zahl \\
\hline Intervention & $7 \mathrm{Hb}$ vs. $12 \mathrm{~g} / \mathrm{dl}$ \\
\hline Ergebnisse & Vermehrt veno-okklusive Erkrankung bei liberal transfundierten Kindern ( 0 vs. 3 Patienten, $p=0,05$ ) \\
\hline Kommentar & $\begin{array}{l}\text { Studie wegen der Entwicklung einer veno-okklusiven Erkrankung bei allen } 3 \text { Patienten der liberalen Gruppe abgebrochen. } \\
\text { Alle } 6 \text { Patienten wurden transfundiert. Neben der größeren EK-Menge in der liberalen Gruppe unterschieden sich die Gruppen } \\
\text { auch in anderen Risikofaktoren für eine veno-okklusive Erkrankung }\end{array}$ \\
\hline Studie(n) & De Almeida 2015 [67] \\
\hline Patientenkollektiv & $\begin{array}{l}\text { Gastrointestinale Onkochirurgie } \\
n=198\end{array}$ \\
\hline Studienziel & Superior study für restriktive Strategie für Mortalität und schwere klinische Komplikationen (30 Tage) \\
\hline Transfusionstrigger & $\begin{array}{l}7 \mathrm{Hb} v s .9 \mathrm{~g} / \mathrm{dl} \\
\text { postoperativ }\end{array}$ \\
\hline Ergebnisse & $\begin{array}{l}\text { Signifikante Unterschiede: } \\
\text { abdominelle Infektionen seltener bei liberaler Transfusion, } \\
\text { kombinierter Endpunkt aus 30-Tage-Morbidität und -Mortalität, 30-Tage-Mortalität und kardiovaskuläre Komplikationen gerin- } \\
\text { ger bei liberaler Transfusion } \\
\text { Keine signifikanten Unterschiede: } \\
\text { Neue Infektionen, Lungen- oder Nierenversagen, septischer Schock, Beatmungsdauer, Vasopressorenbedarf, Wiederaufnahmera- } \\
\text { te Intensivstation, Liegedauer }\end{array}$ \\
\hline Kommentar & Kein Unterschied bei prä-/intraoperativen Transfusionen \\
\hline Studie(n) & DeZern 2016 [68] \\
\hline Patientenkollektiv & $\begin{array}{l}\text { Akute Leukämie } \\
n=89\end{array}$ \\
\hline Studienziel & $\begin{array}{l}\text { Feasibility-Studie zur Vorbereitung einer multizentrischen Studie. } \\
\text { Prüfung Effektivität der Rekrutierung, physiologische Toleranz gegenüber niedrigem Trigger, Gruppenwechsel, Sicherheit } \\
\text { Infektionen in Studie nicht untersucht }\end{array}$ \\
\hline Intervention & $7 \mathrm{Hb}$ vs. $8 \mathrm{~g} / \mathrm{dl}$ \\
\hline Ergebnisse & $\begin{array}{l}\text { Keine signifikanten Unterschiede: } \\
\text { Mortalität, Länge der Krankenhaus-Liegezeit, Fatigue-Scores, Blutungsereignisse, Episoden neutropenischen Fiebers und Anspre- } \\
\text { chen auf die Chemotherapie }\end{array}$ \\
\hline Kommentar & $\begin{array}{l}\text { Keine Angaben zum Anteil transfundierter Patienten } \\
\text { Signifikanter Unterschied bei der medianen EK-Anzahl } 8 \text { vs. } 10\end{array}$ \\
\hline Studie(n) & Bergamin 2017 [69] \\
\hline Patientenkollektiv & $\begin{array}{l}\text { Onkologische Patienten mit septischem Schock } \\
n=300\end{array}$ \\
\hline Studienziel & $\begin{array}{l}\text { Superiority trial: } \\
\text { Restriktive Strategie verringert 28-Tage Mortalität } \\
\text { Infektionen in Studie nicht untersucht }\end{array}$ \\
\hline
\end{tabular}


Tab. 2 (Fortsetzung)

\begin{tabular}{ll}
\hline Studie(n) & Bergamin 2017 [69] \\
\hline Transfusionstrigger & $7 \mathrm{Hb}$ vs. $9 \mathrm{~g} / \mathrm{dl}$ \\
Ergebnisse & $\begin{array}{l}\text { Signifikanter Unterschied: } \\
\text { 90 Tage-Mortalität bei liberaler Strategie geringer } \\
\text { Keine signifikanten Unterschiede: } \\
\text { 28-Tage-Mortalität, Beatmungsdauer, Nierenersatzverfahren, Bedarf an inotropen Medikamenten, Myokardinfarktrate, Schlagan- } \\
\text { fallrate, Extremitätenischämie, Darmischämie, Intensivstation-Wiederaufnahmerate, Krankenhaus-Liegezeit }\end{array}$ \\
& Im Median 1 Transfusion mehr im liberalen Transfusionsarm verabreicht $(p=0,001)$
\end{tabular}

Tab. 3 Studiencharakteristika und Ergebnisse von RCT zu Auswirkungen von EK-Transfusionen bei neurologischen Intensivpatienten

\begin{tabular}{|c|c|}
\hline Studie(n) & Naidech 2010 [71] \\
\hline Patientenkollektiv & $\begin{array}{l}\text { Subarachnoidalblutung } \\
n=44\end{array}$ \\
\hline Studienziel & $\begin{array}{l}\text { Machbarkeit und Sicherheit von höherem } \mathrm{Hb} \\
\text { Hypothesen: } \\
\mathrm{Hb} \geq 11,5 \mathrm{~g} / \mathrm{dl} \text { erhöht nicht die Anzahl der Fiebertage }>38^{\circ} \mathrm{C} \text { bzw. verringert nicht die Anzahl beatmungsfreier Tage (Sicherheit) } \\
\text { Höherer } \mathrm{Hb} \text {-Zielwert führt zu höherem } \mathrm{Hb} \text { im Studienzeitraum (Machbarkeit) }\end{array}$ \\
\hline Intervention & Ziel-Hb: 10 vs. $11,5 \mathrm{~g} / \mathrm{dl}$ \\
\hline Ergebnisse & $\begin{array}{l}\text { Keine signifikanten Unterschiede: } \\
\text { Fiebertage, respiratorische Insuffizienz, Schlaganfallrate, NIH-Stroke Scale Score an Tag 14, körperliche Unabhängigkeit nach der } \\
\text { modifizierten Rankin-Skala an Tag } 14 \text { und an Tag 28; beatmungsfreie Tage; Lungenödem, symptomatische Vasospasmen }\end{array}$ \\
\hline Kommentar & $\begin{array}{l}\text { Pilotstudie } \\
\text { Kein signifikanter Unterschied im Anteil der transfundierten Patienten, Signifikanter Unterschied nur bei medianer EK-Menge ( } 2 \\
\text { vs. } 3 ; p<0,05)\end{array}$ \\
\hline Studie(n) & Robertson 2014 [72] \\
\hline Patientenkollektiv & $\begin{array}{l}\text { Schädel-Hirn-Trauma } \\
n=200\end{array}$ \\
\hline Studienziel & $\begin{array}{l}\text { 1. Bewertung Einfluss Erythropoietin auf neurologisches Outcome } \\
\text { 2. Vorteile eines Hb von } 10 \mathrm{~g} / \mathrm{dl} \text { überwiegen Transfusionsrisiken } \\
\text { Primäroutcome: Glasgow Outcome Score } \\
\text { Primäres Sicherheitsoutcome: Mortalität, ARDS, Infektionen }\end{array}$ \\
\hline Transfusionstrigger & $7 \mathrm{Hb}$ vs. $10 \mathrm{~g} / \mathrm{dl}$ \\
\hline Ergebnisse & $\begin{array}{l}\text { Keine signifikanten Unterschiede: } \\
\text { Infektiöse Komplikationen: Pneumonie, Harnwegsinfekte, Ventrikulitis und Bakteriämien } \\
\text { Glasgow Outcome Score nach } 6 \text { Monaten, Grad der körperlichen Einschränkung, Lungenversagen (ARDS) } \\
\text { Signifikante Unterschiede: } \\
\text { Thromboembolische Komplikationen (Lungenembolie und/oder Beinvenenthrombose) häufiger in der liberal transfundierten } \\
\text { Gruppe }\end{array}$ \\
\hline Kommentar & $\begin{array}{l}2 \times 2 \text {-faktorielles Design } \\
\text { (Transfusionstrigger } 7 \text { vs. } 10 \mathrm{~g} / \mathrm{dL} \text { und Erythropoietin vs. Placebo) }\end{array}$ \\
\hline
\end{tabular}

eine erhöhte Infektionsinzidenz bei liberaler Transfusionsstrategie gab. Für die Mortalität/schwere Komplikationen zeigte sich in dieser Patientengruppe bei liberaler Transfusionsstrategie insgesamt eine geringere Mortalität.

Eine weitere Studie [70] hat in einem RCT Effekte von unterschiedlichen Transfusionsgrenzwerten bei onkologischen Patienten untersucht. In dieser Machbarkeitsstudie wurde die Lebensqualität der Patienten untersucht, z.T. mit selbst auszufüllenden Fragebögen und Anä-
mie-Symptomskalen. Eine Auswertung hinsichtlich möglicher TRIM ist nicht sinnvoll.

\subsubsection{Neurologische Intensivpatienten}

$\mathrm{Zu}$ den möglichen Effekten unterschiedlicher Transfusionstrigger bei neurologischen Intensivpatienten wurden zwei Studien mit insgesamt 244 Patienten betrachtet (- Tab. 3).

Die infektiösen Komplikationen bei neurologischen Intensivpatienten waren in diesen Studien nicht unterschiedlich. In einer Studie [72] fand sich in einer post hocAnalyse, dass die Rate thromboembolischer Komplikationen (Lungenembolie, tiefe Beinvenenthrombose) im liberalen Transfusionsarm erhöht war. Dies steht jedoch aller Wahrscheinlichkeit nach nicht mit einer TRIM in Zusammenhang.

Ein weiteres RCT bei neurointensivmedizinischen Patienten [73] untersuchte vergleichend die Messung der Sauerstoffsättigung bzw. einen Hb-Trigger $(8,6 \mathrm{~g} / \mathrm{dl})$ zur Transfusion. Primäres Stu- 
Tab. 4 Studiencharakteristika und Ergebnisse eines RCT zu Auswirkungen von EK-Transfusionen bei Patienten mit oberen gastrointestinalen Blutungen

\begin{tabular}{|c|c|}
\hline Studie(n) & Villanueva 2013 [74] \\
\hline Patientenkollektiv & $\begin{array}{l}\text { Obere gastrointestinale Blutung } \\
n=921\end{array}$ \\
\hline Studienziel & $\begin{array}{l}\text { Superior Studie für restriktive Strategie } \\
\text { Primäroutcome: 45-Tage-Mortalität (alle Ursachen) } \\
\text { Sekundäroutcomes: Blutungsrate, Komplikationsrate (assoziiert mit aktiver Therapie und/oder Krankenhaus-Aufenthaltsverlän- } \\
\text { gerung) }\end{array}$ \\
\hline Transfusionstrigger & $7 \mathrm{Hb}$ vs. $9 \mathrm{~g} / \mathrm{dl}$ \\
\hline Ergebnisse & $\begin{array}{l}\text { Keine signifikanten Unterschiede: } \\
\text { Infektionen einschließlich nosokomialer Infektionen } \\
\text { Schlaganfall, Akutes Koronarsyndrom, Nierenversagen, } \\
\text { Signifikante Gruppenunterschiede: } \\
\text { 45-Tage-Mortalität, Komplikationen, Reblutungsrate Transfusionsreaktionen, transfusion-associated cardiac overload (TACO), } \\
\text { kardiale Komplikationen und Krankenhaus-Liegezeit schlechter bei liberalem Transfusionsregime }\end{array}$ \\
\hline Kommentar & $\begin{array}{l}\text { Besonders stark erhöhte Mortalität liberal transfundierter Patienten bei Leberzirrhose Child Pugh A oder B. } \\
\text { Anstieg des hepato-venösen Druckgradienten innerhalb der ersten 2-3 Tage nur bei liberal transfundierten Patienten. } \\
\text { Tendenziell höhere Volumengabe bei liberal transfundierten Patienten }\end{array}$ \\
\hline
\end{tabular}

dienziel war die Erfassung der Transfusionen, die im Hb-Trigger-Arm signifikant höher lag. Für die ebenfalls untersuchten klinischen Outcomes, wie Dauer der Intensivbehandlung oder Mortalität, reichte die Power der Studie nicht aus. Daher wird sie nicht in die Gesamtbewertung hinsichtlich TRIM einbezogen.

\subsubsection{Patienten mit oberer gastrointestinaler Blutung}

$\mathrm{Zu}$ den möglichen Effekten unterschiedlicher Transfusionstrigger bei Intensivpatientinnen und -patienten mit einer oberen gastrointestinalen Blutung wurde eine Studie mit insgesamt 921 Patienten betrachtet (• Tab. 4).

In dieser Studie zeigte sich kein signifikanter Unterschied in der Häufigkeit von Infektionen zwischen den Studiengruppen. Jedoch war die 45-Tage-Mortalität der liberal transfundierten Gruppe signifikant höher.

Gleiches gilt für weitere untersuchte Endpunkte (z. B. Reblutungsrate, Krankenhausliegezeit, thromboembolische und ischämische Komplikationen).

Bei der Interpretation dieser Studiendaten sollte beachtet werden, dass die liberale Transfusionsgruppe zusätzlich zu dem höheren Transfusionsvolumen an EK auch tendenziell mehr sonstige Volumentherapie erhalten hatte, welches das Risiko einer Nachblutung und der Mortalität beeinflusst haben könnte. Hierfür spricht auch ein Anstieg des hepato-venösen Druckgradienten nur bei liberal trans- fundierten Patienten und eine höhere Inzidenz von Volumenüberladung (TACO).

Eine weitere große prospektive randomisierte Studie mit 936 Patienten [75] untersuchte im Rahmen einer Machbarkeitsstudie auch die 28-Tage Mortalität sowie weitere klinische Auswirkungen einschließlich Infektionen. Da die Untersuchung weder einen signifikanten Unterschied beim Anteil transfundierter Patienten ( $46 \%$ vs. $33 \%, p=0,23$ ) noch beim durchschnittlichen Transfusionsbedarf $(1,9$ EKs vs. 1,2 EKs, $p=0,12)$ in der liberalen und restriktiven Gruppe aufwies, ist sie für die Bewertung der Ergebnisse hinsichtlich TRIM ungeeignet.

\subsubsection{Patienten der Hochrisiko- und elektiven Herzchirurgie}

Insgesamt wurden 7947 Patienten in vier Studien untersucht, in der Pilotstudie von Shehata et al. [76] speziell elektive Patienten $(n=50)$ mit einem Hoch-Risikoprofil für perioperative Komorbidität oder Mortalität (• Tab. 5).

Die Rate infektiöser Komplikationen wies in allen Studien, die diesen Endpunkt untersuchten, ebenso wie alle anderen klinischen Endpunkte keinen Unterschied zwischen den Studienarmen auf.

Die Mortalität war in allen Studien bezogen auf den primären Studienzeitraum nicht unterschiedlich. In der Studie von Murphy et al. [77] war als sekundärer Endpunkt die 90-Tage-Mortalität (bei nicht unterschiedlicher 30-Tage-Mortali- tät) im liberalen Transfusionsarm signifikant niedriger.

Auch Metaanalysen randomisierter Studien mit herzchirurgischen Patienten $[80,81]$, bei denen in älteren Studien zum Teil noch nicht-leukozytendepletierte EK transfundiert wurden, zeigen keine Unterschiede bei Morbidität oder Mortalität.

Ein weiteres RCT [82] untersuchte den Gerinnungsstatus in Anhängigkeit vom Transfusionstrigger und adressierte als weitere Komplikationen in erster Linie Blutungen und keine möglichen TRIMEffekte der Transfusion.

\subsubsection{Patienten mit akutem oder stabilem Koronarsyndrom}

$\mathrm{Zu}$ den möglichen Effekten unterschiedlicher Transfusionstrigger bei Patienten mit akutem oder stabilem Koronarsyndrom wurden in zwei Pilotstudien insgesamt 155 Patienten betrachtet (• Tab. 6).

Die Rate von infektiösen Komplikationen wie Pneumonien und Bakteriämien war in der Studie von Carson et al. [84] nicht signifikant verschieden. In der Studie von Cooper et al. [83] wurde die Infektionshäufigkeit nicht erfasst.

In der Studie von Cooper et al. [83] zeigte sich ein signifikanter Unterschied bezüglich des primären klinischen Sicherheitsendpunktes (kombiniert Krankenhaus-Mortalität, erneuter Myokardinfarkt, neue oder verschlechterte Herzinsuffizienz), der hauptsächlich auf einen höheren Anteil an neuer oder ver- 
Tab. 5 Studiencharakteristika und Ergebnisse von RCT zu Auswirkungen von EK-Transfusionen bei Patienten der Hochrisiko- und elektiven

Herzchirurgie

Studie(n) Shehata 2012 [76]

Patientenkollektiv Hoch-Risiko herzchirurgische Patienten $n=50$

Studienziel Feasibility-Studie

Primär: Adhärenz zu Transfusionstriggern

Sekundär: Mortalität (alle Ursachen), Aufenthaltsdauer

Transfusionstrigger Intraoperativ: $7 \mathrm{Hb} v \mathrm{H} .9,5 \mathrm{~g} / \mathrm{dL}$

Postoperativ: $7,5 \mathrm{Hb}$ vs. $10 \mathrm{~g} / \mathrm{dL}$

Ergebnisse

Keine signifikanten Unterschiede:

Infektionen: Pneumonie, Sepsis

Katecholaminbedarf $>24 \mathrm{~h}$, postoperativer Myokardinfarkt, Nierenfunktion, Schlaganfall, Lungenembolie/Beinvenenthrombose, Multiorganversagen, Reintubationsrate, Intubation $>48$ h, Krankenhaus-Liegezeit $>11$ Tage, Intensivstation-Liegezeit $>4$ Tage, durchschnittliche Krankenhaus-Liegezeit

Kommentar _ -

Studie(n) Murphy 2015 [77]

Patientenkollektiv Herzchirurgie

$n=2003$

Studienziel Primäroutcome: Composite aus postoperativen Infektionen und Ischämien

Sekundäroutcomes: 90-Tage-Mortalität, einzelne Organkomplikationen, Liegezeit und Kosteneffektivität

Transfusionstrigger $\quad 7,5 \mathrm{Hb}$ vs. $9 \mathrm{~g} / \mathrm{dl}$

Ergebnisse Keine signifikanten Unterschiede:

Kombinierter Endpunkt (schwere Infektion oder ischämisches Ereignis), infektiöses Ereignis, Sepsis, Wundinfektion, Ischämisches Ereignis, Schlaganfall, Myokardinfarkt, Mesenterialinfarkt, akute Nierenschädigung, Liegezeit, klinisch signifikante pulmonale Komplikationen

Signifikanter Unterschied:

90 Tage-Mortalität niedriger bei liberaler Transfusionsstrategie

\begin{tabular}{ll} 
Kommentar & - \\
Studie(n) & Mazer 2017 [78] \\
\hline Patientenkollektiv & $\begin{array}{l}\text { Herzchirurgie } \\
n=5092\end{array}$ \\
\hline
\end{tabular}

Studienziel Non inferiority-Studie für restriktive Transfusion

Primäroutcome: Composite aus Tod, Herzversagen und Nierenversagen

Sekundäroutcomes: Infektionen und diverse Faktoren wie Liegezeit, Delir

Transfusionstrigger $\quad 7,5 \mathrm{Hb}$ vs. 9,5 g/dl intraoperativ und auf Intensivstation;

$7,5 \mathrm{Hb}$ vs. 8,5 g/dl auf Normalstation

Ergebnisse

Keine signifikanten Unterschiede:

Infektionsrate (sekundärer Endpunkt)

kombinierter Endpunkt (Primäroutcome) sowie alle sekundären Endpunkte: Intensivstation-Behandlungsdauer, Hospitalisierungszeit, Beatmungsdauer, Herzzeitvolumen, Darmischämie, akute Nierenschädigung, Krampfanfälle, Delirium und Enzephalopathien

Kommentar Auch in Subgruppenanalyse wurden keine Unterschiede beobachtet (ältere Patienten, Diabetes, Operationsart, chronische Atemwegserkrankung, Nierenerkrankung, Geschlecht, linksventrikuläre Funktion)

Studie(n) Koch 2017 [79]

Patientenkollektiv Herzchirurgie

$n=722$

Studienziel Non-Inferior Studie für restriktive Strategie Morbidität, Mortalität, EK-Gebrauch

Transfusionstrigger Hämatokrit $24 \%$ vs. $28 \%$

Ergebnisse Keine signifikanten Unterschiede:

Infektionen

Kombinierter Endpunkt aus Mortalität und Morbidität, neurologische Komplikationen, pulmonale Komplikationen, Nierenversagen, Beatmungspflicht über mehr als $24 \mathrm{~h}$, Intensiv- oder Krankenhausbehandlungsdauer

Kommentar Nach persönlicher Mitteilung des Autors waren alle EK leukozytendepletiert.

Die Studie wurde wegen fehlender Unterschiede zwischen den Behandlungsgruppen (a priori definierte Futility Grenze) vorzeitig abgebrochen 
Tab. 6 Studiencharakteristika und Ergebnisse von RCT zu Auswirkungen von EK-Transfusionen bei Patienten mit akutem oder stabilem

Koronarsyndrom

\begin{tabular}{|c|c|}
\hline Studie(n) & Cooper 2011 [83] \\
\hline Patientenkollektiv & $\begin{array}{l}\text { Akuter Myokardinfarkt } \\
n=45\end{array}$ \\
\hline Studienziel & $\begin{array}{l}\text { Primäroutcomes: Anzahl EK, Hämatokrit, } \\
\text { Tod, Re-Infarkt, Herzinsuffizienz (als Composite) } \\
\text { Infektionen nicht untersucht }\end{array}$ \\
\hline Transfusionstrigger & $8 \mathrm{Hb}$ vs. $10 \mathrm{~g} / \mathrm{d}$ \\
\hline Ergebnisse & $\begin{array}{l}\text { Signifikante Unterschiede: } \\
\text { Primärer Sicherheitsendpunkt (kombiniert Krankenhaus-Mortalität, erneuter Myokardinfarkt, neue oder verschlechterte Herzin- } \\
\text { suffizienz) schlechter bei liberal transfundierten Patienten } \\
\text { Kein Signifikanter Unterschied: } \\
\text { 30-Tage-Mortalität }\end{array}$ \\
\hline Kommentar & $\begin{array}{l}\text { Pilotstudie, keine Angaben zur Volumentherapie } \\
\text { Liberal transfundierte Patienten waren im Mittel älter und wiesen mehr Vorerkrankungen bzw. schwerere Krankheitsstadien auf }\end{array}$ \\
\hline Studie(n) & Carson 2013 [84] \\
\hline Patientenkollektiv & $\begin{array}{l}\text { Akutes Koronarsyndrom oder stabile Angina pectoris und } \\
\mathrm{Hb}<10 \mathrm{~g} / \mathrm{dl} \\
n=110\end{array}$ \\
\hline Studienziel & $\begin{array}{l}\text { Primäroutcome: Composite aus Tod, Reinfarkt und ungeplanter Angioplastie } \\
\text { Sekundäroutcomes: Pneumonie, Bakteriämie und andere nicht-infektiöse klinische Komplikationen }\end{array}$ \\
\hline Transfusionstrigger & $8 \mathrm{Hb}$ vs. $10 \mathrm{~g} / \mathrm{dl}$ \\
\hline Ergebnisse & $\begin{array}{l}\text { Keine signifikanten Unterschiede: } \\
\text { Infektionen: Pneumonie und Bakteriämie } \\
\text { Kombinierte Endpunkt (Tod, Myokardinfarkt und instabile Angina pectoris), Myokardinfarkt, ungeplante koronare Revaskularisa- } \\
\text { tion, Schlaganfall, Herzinsuffizienz, Stentthrombose, Lungenembolie oder Beinvenenthrombose } \\
\text { Signifikanter Unterschied: } \\
\text { 30-Tage Mortalität niedriger bei liberal Transfundierten }\end{array}$ \\
\hline Kommentar & $\begin{array}{l}\text { Multizentrische Pilotstudie; Patientenalter in der restriktiven Gruppe höher (im Median } 7 \text { Jahre). } \\
\text { Leukozytendepletion von } 92 \text { bzw. } 95 \text { \% der transfundierten EK }\end{array}$ \\
\hline
\end{tabular}

schlechterter Herzinsuffizienz in der liberalen Gruppe zurückzuführen war. Ob sich der Unterschied möglicherweise durch das höhere Alter und die häufigeren Vorerkrankungen bei den Patientinnen und Patienten der liberalen Gruppe erklären lassen, haben die Autoren nicht untersucht. Die 30-Tage-Mortalität unterschied sich in den beiden Gruppen nicht.

In der Studie von Carson et al. [84] traten in der liberalen Gruppe weniger Ereignisse des primären Outcomes (Kombinierter Endpunkt 30-Tage-Mortalität/ Myokardinfarkt/Revaskularisation) auf bei der 30-Tage-Mortalität war der Unterschied signifikant. Ein möglicher Einfluss des höheren Durchschnittalters in der restriktiven Behandlungsgruppe kann nicht ausgeschlossen werden.

\subsubsection{Patientinnen mit postpartaler Anämie}

534 Patientinnen mit einer postpartalen Anämie wurden in zwei Studien zum
Vergleich Transfusion versus abwartende Strategie bzw. versus i.v. Eisen eingeschlossen (• Tab. 7).

In der Studie von Prick et al. [56] zeigten sich keine Unterschiede im Auftreten von Infektionen bzw. infektiösen Komplikationen. Infektiöse Komplikationen wurden in der Studie von Holm et al. [55] nicht als Endpunkt untersucht.

\subsubsection{Patienten mit respiratorischer Insuffizienz und Beatmungspflichtigkeit}

Eine Studie untersuchte 100 Patienten mit prolongierter Beatmungspflichtigkeit (- Tab. 8).

Das Auftreten von infektiösen Komplikationen wurde in dieser Studie nicht untersucht. Die Zahl antibiotikafreier Tage war wie die weiteren klinischen Endpunkte (Intensivstation- und Krankenhausliegezeit, beatmungsfreie Tage innerhalb von $60 \mathrm{Ta}$ gen Beobachtungszeitraum etc.) nicht unterschiedlich zwischen den Transfusionsarmen.

\subsubsection{Patienten mit septischem Schock}

Dieses Krankheitsbild wurde in einer Studie untersucht (• Tab. 9).

Der Einfluss eines Transfusionsregimes auf das Auftreten von infektiösen Komplikationen bei Patienten mit septischem Schock kann anhand dieser Studie nicht beurteilt werden, da infektiöse Komplikationen nicht als Studienendpunkte untersucht wurden. Weder die 90-Tage-Mortalität als primärer Studienendpunkt noch die weiteren klinischen Endpunkte zeigten einen Unterschied zwischen den Gruppen.

\subsubsection{Patienten mit schweren Verbrennungen}

In einer multizentrischen Studie wurden 345 Patienten mit Verbrennung von mindestens $20 \%$ der Körperoberfläche untersucht (• Tab. 10).

Obwohl liberal transfundierte Patienten etwa die doppelte Anzahl Erythrozytenkonzentrate erhielten, zeigten sich keine 
Tab. 7 Studiencharakteristika und Ergebnisse von RCT zu Auswirkungen von EK-Transfusionen bei Patientinnen mit postpartaler Anämie

\begin{tabular}{|c|c|}
\hline Studie(n) & Prick 2014 [56] \\
\hline Patientenkollektiv & $\begin{array}{l}\text { Postpartale Anämie } 4,8-7,9 \mathrm{~g} / \mathrm{dL} \\
n=521\end{array}$ \\
\hline Studienziel & $\begin{array}{l}\text { Non-inferiority trial } \\
\text { Primäres Outcome: Physical fatigue }\end{array}$ \\
\hline Intervention & Transfusion vs. Abwarten und keine Transfusion \\
\hline Ergebnisse & $\begin{array}{l}\text { Keine signifikanten Unterschiede: } \\
\text { Spezifische Infektionshäufigkeiten (Wundinfektion, Endometritis, Harnwegsinfektion, lokale Infektion) } \\
\text { Signifikanter Unterschied: } \\
\text { Körperlicher Fatigue Score an Tag } 3 \text { und } 7 \text { nach der Geburt niedriger bei liberaler Transfusion }\end{array}$ \\
\hline Kommentar & Klinische Bedeutung der Unterschiede im Fatigue-Score ist gering \\
\hline Studie(n) & Holm 2017 [55] \\
\hline Patientenkollektiv & $\begin{array}{l}\text { Postpartale Anämie } \\
\text { Blutverlust }>1000 \mathrm{~mL}, \mathrm{Hb} 5,6-8,1 \mathrm{~g} / \mathrm{dL} \\
n=13\end{array}$ \\
\hline Studienziel & $\begin{array}{l}\text { Machbarkeitsstudie } \\
\text { Primäres Outcome: Physical Fatigue Score } \\
\text { Sekundäroutcomes: Erschöpfung, Depression, Laborparameter }\end{array}$ \\
\hline Intervention & Eisen i.v. vs. Transfusion \\
\hline Ergebnisse & $\begin{array}{l}\text { Keine signifikanten Unterschiede: } \\
\text { primäres Outcome } \\
\text { Ein Fall von Fieber in der transfundierten Gruppe }\end{array}$ \\
\hline Kommentar & - \\
\hline
\end{tabular}

Tab. 8 Studiencharakteristika und Ergebnisse von RCT zu Auswirkungen von EK-Transfusionen bei Patienten mit respiratorischer Insuffizienz und Beatmungspflichtigkeit

\begin{tabular}{|c|c|}
\hline Studie(n) & Walsh 2013 [85] \\
\hline Patientenkollektiv & $\begin{array}{l}\text { Patienten } \geq 55 \text { Jahre und } \geq 4 \text { Tage Beatmung } \\
n=100\end{array}$ \\
\hline Studienziel & $\begin{array}{l}\text { Machbarkeitsstudie } \\
\text { Primäres Outcome: Unterschied in Hb-Konzentration } \\
\text { Sekundäre Outcomes: Mortalität, beatmungsfreie Zeit, antibiotikafreie Zeit, Health related Quality of Life (HRQoL), körperliche } \\
\text { Funktion } \\
\text { Infektionen nicht untersucht }\end{array}$ \\
\hline Transfusionstrigger & $7 \mathrm{Hb}$ vs. $9 \mathrm{~g} / \mathrm{dl}$ \\
\hline Ergebnisse & $\begin{array}{l}\text { Keine signifikanten Unterschiede: } \\
\text { Mortalität, Intensivstation- und Krankenhaus-Liegezeit, Beatmungs- und Antibiotika-freie Tage innerhalb von } 60 \text { Tagen, River- } \\
\text { mead-Mobilitätsindex, SF-12 physischer Funktions- und mentaler Komponentenscore sowie Rate an akuten Koronarsyndromen } \\
\text { und thromboembolischen Komplikationen }\end{array}$ \\
\hline Kommentar & $\begin{array}{l}\text { Pilotstudie } \\
69 \% \text { der Patienten hatten bereits EK während des Aufenthalts erhalten }\end{array}$ \\
\hline
\end{tabular}

signifikanten Unterschiede bei den infektiösen Komplikationen (Bakteriämie, Pneumonie- und Wundinfektionsrate) oder bei Mortalität oder Morbidität im Vergleich zu restriktiv transfundierten Patienten.

\subsubsection{Zusammenfassung}

Die Ergebnisse von 22 prospektiven RCTs mit 12.974 Patientinnen und Patienten in 10 unterschiedlichen Behandlungsgruppen/Indikationen bei Erwachsenen zeigen keine konsistenten und signifikant erhöhte Raten an Infektionen oder (post)infektiösen Komplikationen bei liberal transfundierten Patienten als mögliche direkte Folge einer TRIM, sofern diese Endpunkte untersucht wurden.

Aus den Studien gibt es nach gegenwärtiger Datenlage keinen Hinweis darauf, dass eine liberale oder restriktive Transfusionsbehandlung im Hinblick auf das Auftreten von Infektionen oder (post) infektiösen Komplikationen, die als Surrogatparameter einer TRIM gewertet werden könnten, über- oder unterlegen war.

Auch eine umfassende Metaanalyse der Cochrane-Library, die jedoch auch Studien mit nicht-leukozytendepletierten EK einschloss, fand bei Analyse von 31 randomisierten Studien mit insgesamt 12.587 Patienten keine Unterschiede im Outcome von liberal und restriktiv transfundierten Patienten, insbesondere keine Unterschie- 


\section{Tab. 9 Studiencharakteristika und Ergebnisse von RCT zu Auswirkungen von EK-Transfusionen bei Patienten mit septischem Schock}

\begin{tabular}{|c|c|}
\hline Studie(n) & Holst 2014 [86] \\
\hline Patientenkollektiv & $\begin{array}{l}\text { Septischer Schock und profunde Anämie } \\
n=998\end{array}$ \\
\hline Studienziel & $\begin{array}{l}\text { Primäroutcome: } 90 \text {-Tage Mortalität } \\
\text { Sekundäroutcomes: Lebenserhaltende Maßnahmen, schwere Nebenwirkungen von Transfusionen, Ischämien, Tage ohne organ- } \\
\text { unterstützende Kreislauf- oder Beatmungstherapie oder Nierenersatztherapie } \\
\text { Infektionen wurden nicht untersucht }\end{array}$ \\
\hline Transfusionstrigger & $7 \mathrm{Hb}$ vs. $9 \mathrm{~g} / \mathrm{dl}$ \\
\hline Ergebnisse & $\begin{array}{l}\text { Keine signifikanten Unterschiede: } \\
\text { 90-Tage- und Langzeit-Mortalität, Rate an Organ-unterstützenden Therapien (Katecholamine, invasive/nicht-invasive Beatmung, } \\
\text { Nierenersatzverfahren), ischämische Ereignisse (Schlaganfall, Myokardinfarkt, mesenteriale Ischämie, Extremitätenischämie), } \\
\text { schwere Nebenwirkungen }\end{array}$ \\
\hline Kommentar & Patienten mit akutem Myokardinfarkt und anderen Vorerkrankungen ausgeschlossen \\
\hline Studie(n) & Palmieri 2017 [87] \\
\hline Patientenkollektiv & $\begin{array}{l}\text { Verbrennung } \geq 20 \% \text { der Körperoberfläche } \\
n=345\end{array}$ \\
\hline Studienziel & $\begin{array}{l}\text { Primäre Outcomes: Überleben, Infektionen, Wundheilung } \\
\text { Stratifiziert für Verbrennungen von } 20-59 \% \text { und } 60+\% \text { Körperoberfläche }\end{array}$ \\
\hline Transfusionstrigger & $7 \mathrm{Hb}$ vs. $10 \mathrm{~g} / \mathrm{dl}$ \\
\hline Ergebnisse & $\begin{array}{l}\text { Keine signifikanten Unterschiede: } \\
\text { Infektionen: Bakteriämie, Pneumonie, Wundinfektionen } \\
\text { 30-Tage-Mortalität, Organversagen, Beatmungsdauer, Zeit bis zur Wundheilung }\end{array}$ \\
\hline Kommentar & $\begin{array}{l}\text { Nach persönlicher Mitteilung des Autors waren über } 99 \% \text { der EK leukozytendepletiert. } \\
\text { Alle Patienten haben im Mittel > } 10 \text { EK erhalten }\end{array}$ \\
\hline
\end{tabular}

de in Bezug auf Pneumonien, Bakteriämien oder Wundinfekte [88]. Demgegenüber ermittelte die Metaanalyse von Rohde et al., die einen Teil der beschrieben Transfusionstrigger-Studien untersuchte, eine höhere Rate schwerwiegender infektiöser Komplikationen bei liberal transfundierten Patienten [89]. Die Unterschiede der Ergebnisse beider Metaanalysen könnten durch Unterschiede bei den eingeschlossenen Studien (Publikationsjahr: Rohde 2014, Carson 2016), unterschiedliche Definitionen für die Zielvariable „schwere Infektionen" und Unterschiede in der Gewichtung der einzelnen Studien in den durchgeführten Metaanalysen erklärbar sein. Aufgrund der differenzierten Metaanalyse unterschiedlicher infektiöser Outcomes („Sepsis/Bakteriämie“, „Pneumonie“ und „Pneumonie oder Wundinfektionen") im neueren Cochrane-Report ist anzunehmen, dass die analysierten Studien keinen signifikanten Unterschied zwischen restriktiver und liberaler Transfusionspraxis in Bezug auf infektiöse Komplikationen aufweisen.
In einzelnen Studien sind Patienten überwiegend im restriktiven Transfusionsarm - beschrieben, die über den Studienzeitraum nicht transfundiert wurden. Der Anteil der im gesamten Behandlungsverlauf (nicht nur während des Studienzeitraums) nicht-transfundierten Patienten wurde jedoch oft nicht angegeben. Weiterhin wurde bei einigen Studien erst postoperativ oder für einen bestimmten Zeitraum für ein Transfusionsregime randomisiert, so dass ein TRIM-Effekt außerhalb des Beobachtungszeitraums nicht abgeschätzt werden kann. Ein separater Vergleich von Subgruppen nicht-transfundierter und transfundierter Patienten innerhalb des Studienarms ist in keiner Studie berichtet worden. Dies wäre auch methodisch problematisch, da hier ein Einfluss der Indikation zur Transfusion (indication bias) erwartbar wäre.

Insgesamt wiesen die vorliegenden Studien nur in einzelnen Fällen Infektionen oder infektionsassoziierte Mortalität als Studienziel auf. Mit Ausnahme der Studien in der Geburtsmedizin wurde zu- dem kein Studienansatz gewählt, bei dem Transfusionen mit anderen Anämietherapien verglichen wurden. Daher besteht Forschungsbedarf für Studien, die mögliche negative TRIM-Effekte als primären Endpunkt in Populationen untersuchen, die sich hinsichtlich der Exposition Transfusion klar unterscheiden.

\subsection{Neugeborene, Kinder und Jugendliche}

Eine mögliche TRIM ist in der Pädiatrie von besonderem Interesse. In retrospektiven Beobachtungsstudien wurde - insbesondere bei Frühgeborenen - zumeist das Auftreten umschriebener Krankheitsbilder mit einer vorherigen Transfusion von EK assoziiert. Beispielhaft sind hier als akute Reaktion ( $<72 \mathrm{~h}$ nach der Transfusion) die transfusionsassoziierte nekrotisierende Enterokolitis (ta-NEC) oder im langfristigen Verlauf die höhergradige Retinopathie (Retinopathy of Prematurity; ROP Stadium $\geq 3$ ) des Frühgeborenen zu nennen [90-94]. In prospektiven RCTs 
Tab. 11 Studiencharakteristika und Ergebnisse des RCT zu Auswirkungen von EK-Transfusionen bei Frühgeborenen

\begin{tabular}{ll} 
Studie(n) & Haiden et al. 2006 [97] \\
\hline Patientenkollektiv & $\begin{array}{l}\text { Frühgeborene } \leq 800 \mathrm{~g} \text { Geburtsgewicht } \\
n=40\end{array}$ \\
$\begin{array}{l}\text { Studienziel } \\
\text { Intervention }\end{array}$ & $\begin{array}{l}\text { Entersuchung der Auswirkung einer kombinierten Erythropoietin/Folat/Eisen/Vitamin B12-Therapie auf Transfusionsindikation } \\
\text { Ergebnisse }\end{array}$ \\
$\begin{array}{l}\text { Signifikanten Unterschiede: } \\
\text { Beatmung in Therapiegruppe häufiger als bei Kontrollen } \\
\text { Keine signifikanten Unterschiede: } \\
\text { Mortalität, Überdruckbeatmung (CPAP), Nekrotisierende Enterocolitis, intraventikuläre Blutungen bzw. Leukomalazie, Retinopa- } \\
\text { thie }\end{array}$ \\
Kommentar & Transfusionsanteil in den Gruppen: $62 \%$ vs. $95 \%$ (Primäroutcome) $(p=0,013)$
\end{tabular}

lassen sich diese Beobachtungen jedoch nicht regelhaft bestätigen.

Bei Neugeborenen, die auf einer neonatologischen Intensiv(überwachungs)Station aufgenommen werden, wird mit hoher Wahrscheinlichkeit die Indikation zu einer Transfusion gestellt. Während der stationären Behandlung erhielten (in Kanada) mehr als $50 \%$ aller Neugeborenen mit einem Gestationsalter von weniger als 30 abgeschlossenen Schwangerschaftswochen und mehr als $80 \%$ aller Frühgeborenen mit einem Geburtsgewicht von weniger als $1000 \mathrm{~g}$ mindestens eine Transfusion von EK [95]. Die Indikation zur EK-Transfusion ist nicht nur von Transfusionsgrenzwerten, sondern von der pathophysiologischen Relevanz der Anämie (z.B. Notwendigkeit von Sauerstoffsupplementation und/oder Beatmung) abhängig.

Unerwünschte Effekte einer Transfusionsbehandlung werden je nach Lebensalter anhand unterschiedlicher Parameter bewertet. Primäres Outcome ist typischerweise die Mortalität innerhalb von $24 \mathrm{~h}$ nach der Transfusion von EK. Zu den primären oder sekundären OutcomeParametern können sowohl infektiöse Komplikationen, bspw. eine bakterielle Infektion bzw. Sepsis, als auch nicht-infektiöse Krankheitskomplikationen wie bronchopulmonale Dysplasie (BPD, definiert durch eine Sauerstoff-Supplementation mit 36 Schwangerschaftswochen), ROP $\geq 3$, NEC $\geq$ Stadium II nach Bell, intraventrikuläre Hämorrhagie (IVH) $\geq$ III und psychomotorische Entwicklungsverzögerungen zählen [96].

In der Kinder- und Jugendmedizin, insbesondere in der Neonatologie, können sehr unterschiedlich konzipierte Stu- dien als Quelle für Informationen zur Frage nach einer TRIM dienen. Solche Studien vergleichen $u$.a.:

- Effekte der EK-Transfusion gegenüber einer Kontrollgruppe ohne Transfusion,

- liberale vs. restriktive Grenzwerte für die Indikationsstellung zur Transfusion von EK,

- höhere gegenüber niedrigeren Transfusionsvolumina,

- Transfusionen von EK vs. Stimulation der Erythropoiese durch rekombinantes humanes Erythropoietin oder seine Derivate (z. B. Darbepoetin).

Bei der Analyse der Daten zur TRIM ist zu beachten, dass - insbesondere in älteren Studien - mitunter nicht-leukozytendepletierte EK transfundiert wurden oder genaue Angaben zur Herstellung des EK fehlen. Die vorliegende Analyse wurde auf solche Studien eingegrenzt, bei denen eindeutig die Transfusion von leukozytendepletierten EK dokumentiert ist. Darüber hinaus sind möglicherweise auch Effekte aufgrund einer sequenziellen Transfusion aus Satellitenbeuteln eines EK zur Reduktion der Spenderexposition vs. einer kurzfristigen Exposition gegenüber multiplen Spendern zu berücksichtigen. Eine Sondersituation ergibt sich aus der Indikation einer Austauschtransfusion bei Neugeborenen mit schwerster Hämolyse bei Blutgruppeninkompatibilität mit einer neonatalen Hämochromatose oder einer anderen, durch maternale Auto-Antikörper vermittelten Erkrankung.

Insgesamt ist die Zahl der Studien, aus denen Rückschlüsse für eine TRIM im Kinder- und Jugendalter gezogen werden können, sehr begrenzt. Innerhalb der Sub- gruppen finden sich für Früh- und Reifgeborene die meisten Informationen.

\subsubsection{Früh- und Reifgeborene}

In einer im Jahr 2016 veröffentlichten Metanalyse aller seit 1990 publizierten RCTs zu restriktiven vs. liberalen Grenzwerten für die Indikation zur EK-Transfusion konnte hinsichtlich der primären Outcome Parameter (Mortalität; BPD, ROP, NEC und IVH) kein signifikanter Unterschied gefunden werden. Eine Metaanalyse $\mathrm{zu}$ sekundären Outcome $\mathrm{Pa}$ rametern, die präziserer auf eine TRIM hindeuten (z. B. Infektionen bzw. Sepsis, immunologische Reaktionen innerhalb von $48 \mathrm{~h}$ nach der Transfusion, Alloimmunisierung), war aufgrund der unzureichenden Datenlage nicht möglich [96].

Insgesamt fällt eine hohe Heterogenität der in diese Metaanalyse eingeschlossenen Studien auf. Es wurden sowohl Studien eingeschlossen, bei denen nicht-leukozytendepletierte EK verwendet wurden, oder bei denen zur Leukozytendepletion keine Aussagen gemacht wurden als auch Studien, in denen keine Unterschiede in der Häufigkeit und Menge der Transfusionen zwischen den Gruppen vorlagen. Eine kleine Studie bei Frühgeborenen mit unterschiedlichem Transfusionsanteil mit leukozytendepletierten EK in den Gruppen untersuchte als sekundäres Outcome auch potenzielle indirekte Marker einer TRIM [97]. Die Ergebnisse sind in - Tab. 11 aufgelistet.

In Kürze werden die Ergebnisse von zwei RCTs vorliegen, die einen Vergleich geeigneter primärer und sekundärer Outcome Parameter nach liberaler vs. restriktiver EK-Transfusion vornehmen und größere Fallzahlen der Studienpati- 
enten beinhalten: a) Das Transfusion of Prematures (TOP) Trial (NCT01702805) mit $n=1824$ Frühgeborenen mit einem Geburtsgewicht $<1000 \mathrm{~g}$ und einem Gestationsalter $<29$ abgeschlossenen Schwangerschaftswochen und b) eine Untersuchung mit dem Titel Effects of transfusion thresholds on neurocognitive outcome (ETTNO) Studie (NCT01393496) mit $n=1013$ Frühgeborenen mit einem Geburtsgewicht zwischen 400 und $999 \mathrm{~g}$.

Hinsichtlich einer möglichen TRIM könnte auch die Frage relevant sein, inwiefern die Lagerungsdauer des EK insbesondere bei sehr unreifen Frühgeborenen (Age of Red Blood Cells in Premature Infants (ARIPI) Trial) einen Einfluss auf die Rate von Störungen der Organfunktion, Infektionen oder die Hospitalisierungszeit haben könnte. In diesem RCT wurde bei Frühgeborenen mit einem Geburtsgewicht $<1500 \mathrm{~g}$ kein Unterschied hinsichtlich der Mortalität und Morbidität (Rate von NEC, ROP, BPD, IVH sowie Blutstrom-Infektion) in Abhängigkeit gefunden, ob die Frühgeborenen mit einem maximal 7 Tage vs. 8 bis 42 Tage gelagerten EK transfundiert wurden [98].

\subsubsection{Kinder und Jugendliche}

Die Datenlage zu einer TRIM ist auch bei kritisch kranken Kindern und Jugendlichen sehr begrenzt ( $\bullet$ Tab. 12). Ebenso wie bei Erwachsenen gibt es anhand von Beobachtungsstudien Hinweise darauf, dass die Transfusion von EK ein unabhängiger Risikofaktor für eine höhere Mortalitäts- und Morbiditätsrate sein könnte $[11,99,100]$. Dies betrifft auch das Auftreten von nosokomialen Infektionen oder Pneumonien [100-102]. Bei diesen sind jedoch stets die oben aufgeführten Möglichkeiten von Verzerrungen (z. B. indication bias) zu berücksichtigen, auch wenn Unterschiede hinsichtlich des Schweregrads der Erkrankung bei den Auswertungen zum Teil berücksichtigt wurden.

Ein RCT, welches 637 pädiatrische Intensivpatienten einschloss, untersuchte Auswirkungen verschiedener Transfusionstrigger u.a. auf Mortalität und nosokomiale Infektionen [101]. In dieser Studie wurde, wie in $\bullet$ Tab. 11 dargestellt, kein signifikanter Unterschied bezüglich der untersuchten Outcomes auch in älteren Kindern gefunden.
In zwei weiteren prospektiven, randomisierten Studien wurde bei Kindern mit kardiochirurgischen Eingriffen kein Unterschied im Outcome beim Vergleich zwischen liberalen $v s$. restriktiven Transfusionsgrenzen gefunden $[102,103]$.

Einige Studien adressierten auch mögliche Effekte von unterschiedlichen Lagerungszeiten der EK vor Transfusion hinsichtlich einer TRIM. Ein RCT untersuchte bei 290 Kindern im Alter von 6-60 Monaten mit Laktat-Azidose bei schwerer Anämie (zumeist aufgrund einer Malaria oder Sichelzell-Erkrankung) die Auswirkung der Lagerungszeit (1-10 Tage vs. 2535 Tage) von leukozytendepletierten EK auf die Normalisierung der Laktatspiegel. In beiden Untersuchungsgruppen fanden sich gleiche Ergebnisse für die Erholung der Laktatspiegel und Elektrolytkonzentrationen, die Normalisierung der zerebralen Oxygenierung, die Rate von Mortalität und schwerer sekundärer Morbidität, so dass sich kein Hinweis auf eine TRIM in Abhängigkeit von der Lagerungsdauer des EK ergab [105].

Auch bei kritisch kranken Kindern $(n=1538)$ im Alter von 3 Tagen bis 16 Jahren wurde in einem multizentrischen RCT (Age of Blood in Children in Pediatric Intensice care (ABC-PICU) Trial) der Effekt der Lagerungszeit des leukozytendepletierten EK ( $\leq 7$ Tage vs. $>14$ Tage) auf eine neue oder progressive Multiorganfunktionsstörung verglichen. Dabei wurden - auch in der altersgewichteten Auswertung - keine Unterschiede hinsichtlich der Mortalität oder der Prävalenz von Multiorganfunktionsstörungen, Atemnotsyndrom oder Sepsis als mögliche Zeichen einer TRIM gefunden [106].

\subsubsection{Zusammenfassung}

Die Frage nach dem Auftreten und der Relevanz von TRIM bei Neugeborenen, Kindern und Jugendlichen kann derzeit nicht sicher beantwortet werden. Aus den RCTs lässt sich eine klinisch relevante TRIM derzeit in allen drei Altersgruppen nicht ableiten. Allerdings sind die derzeit gängigen Parameter für das Outcome möglicherweise nicht sensitiv genug. Eventuell ist auch der Beobachtungszeitraum zu kurz. In Beobachtungsstudien weist die klinisch relevante Anämie vermutlich primär auf den Schweregrad der Grunderkrankung hin (Bias s. oben).

Insbesondere bei Frühgeborenen müssen mögliche immunmodulatorische Auswirkungen der Transfusion von EK, für die es in Laboruntersuchungen (z.B. an Subpopulationen der weißen Blutkörperchen) und Beobachtungsstudien Hinweise gibt, geprüft werden. Hierbei könnten die zwangsläufigen entwicklungsabhängigen Unterschiede eines adulten Spenderpräparats in einem neonatalen Körper eine übergeordnete oder besondere Rolle spielen. Hinsichtlich der immunologischen Auswirkungen von Transfusionen von EK bei Neugeborenen und Kindern besteht großer Forschungsbedarf.

\section{Der Einfluss der Transfusion von Erythrozytenkonzentraten auf Krebserkrankungen}

Seit der Entdeckung von tumorspezifischen Antigenen wird davon ausgegangen, dass das körpereigene Immunsystem eine wichtige Rolle bei der Elimination von malignen Zellen spielt [107, 108]. Seit Anfang der 1970er Jahre ist ein Zusammenhang von Immunsuppression und erhöhtem Risiko für verschiedene Krebserkrankungen umfassend dokumentiert. Eine erhöhte Inzidenz von Krebserkrankungen wird sowohl bei Patienten mit primären Immundefekten als auch bei Patienten unter immunsuppressiver Therapie, beispielsweise nach Organtransplantationen, beobachtet [109-111].

Dass auch allogene Bluttransfusionen immunsuppressive Effekte auslösen können, wurde bereits zu Beginn der 1970er Jahre beschrieben. Opelz und Terasaki beobachteten positive Auswirkungen prophylaktischer Bluttransfusionen auf das Überleben von Nierentransplantaten durch Vermeidung immunologischer Abstoßungsreaktionen [112]. Die Studien ließen den Schluss zu, dass die von den Transfusionen verursachten immunsuppressiven Effekte vor allem auf zelluläre Blutkomponenten zurückzuführen sind [113]. Weitere Untersuchungen zu prophylaktischen Bluttransfusionen bei Nierentransplantationen veranlassten Gantt 1981 zu der Vermutung, dass Bluttransfusionen bei Krebspatienten aufgrund ähnlicher Immunmechanismen das Rezidiv- 
Tab. 12 Studiencharakteristika und Ergebnisse von RCT zu Auswirkungen von EK-Transfusionen bei Kindern und Jugendlichen

\begin{tabular}{ll}
\hline Studie(n) & Lacroix 2007 [101] \\
\hline Patientenkollektiv & Stabile pädiatrische Intensivpatienten \\
& 3 Altersgruppen $(\leq 28 \mathrm{~d}, 29-364 \mathrm{~d},>364 \mathrm{~d})$ \\
& $n=637$
\end{tabular}

Studienziel Prüfung der Nichtunterlegenheit einer restriktiven Transfusionsstrategie hinsichtlich eines multiplen Organversagens Primäroutcome: neues oder fortschreitendes multiples Organversagen Sekundäroutcome: 28-Tage-Mortalität*, Paediatric logistic organ dysfunction (PELOD), Sepsis, nosokomiale respiratorische bzw. Katheter-assoziierte Infektionen, Transfusionsreaktionen, Intensivstation/Krankenhausaufenthalt, Nebenwirkungen

Transfusionstrigger Hb 7 vs. $9,5 \mathrm{~g} / \mathrm{dl}$

Ergebnisse Keine signifikanten Unterschiede:

Neues oder fortschreitendes Multiorganversagen

28-Tage-Mortalität, nosokomiale Infektionen, Beatmungsdauer, Aufenthalt auf Intensivstation, Transfusionsreaktionen

Kommentar Transfusionsanteil in den Gruppen: $46 \%$ vs. $98 \%$

*Widerspruch zwischen Methodenbeschreibung und Ergebnisdarstellung/Trial-Registrierung

Studie(n)

Cholette 2011 [102]

Patientenkollektiv Kinder mit univentrikularisiertem Herz und cavopulmonaler Anastomose

$n=60$

Studienziel Non-inferior study für restriktive Strategie

Primäroutcome: arterieller Laktatwert

Sekundäroutcomes: arteriovenöser und arteriocerebraler $\mathrm{O}_{2}$-Gehalt, klinische Outcomes

Transfusionstrigger

$\mathrm{Hb} 9 \mathrm{vs.} 13 \mathrm{~g} / \mathrm{dl}$, postoperativ

Ergebnisse

Keine signifikanten Unterschiede:

arterieller Laktat-Wert,

arteriovenöser und arteriocerebraler $\mathrm{O}_{2}$-Gehalt, mittlere Beatmungsdauer, mittlerer Intensivstations-Aufenthalt, mittlere Krankenhausliegezeit, Überleben bis Entlassung

Kommentar

Transfusionsanteil in den Gruppen: $37 \%$ vs. $97 \%$

Keine Angaben zu intraoperativen Transfusionen

Power der Studie nicht ausgelegt für Signifikanztests zu Unterschieden der klinischen Outcomes

Studie(n)

De Gast-Bakker 2013 [103]

Patientenkollektiv Operationsbedürftiger angeborener nicht zyanotischer Herzfehler

$n=107$

Studienziel Non-inferiority-Studie für restriktive Transfusionsstrategie

Primäres Outcome: Dauer des Krankenhausaufenthaltes

Sekundäre Outcomes: Aufenthaltsdauer auf Intensivstation, Dauer der Beatmung, Komplikationen, unerwünschte Wirkungen und Kosten

Transfusionstrigger $\quad H b 8 \mathrm{~g} / \mathrm{dl}$ vs. $10,8 \mathrm{~g} / \mathrm{dl}$

Ergebnisse Keine signifikanten Unterschiede:

Intensivstation/Krankenhausaufenthalt, Dauer der Beatmung, Komplikationen

Kommentar Alle Kinder wurden transfundiert. Es bestand lediglich ein Unterschied im Volumen der insgesamt verabreichten EK (259 vs. $186 \mathrm{ml} /$ Patient/in)

Studie(n) Cholette 2017 [104]

Patientenkollektiv Operationsbedürftiger angeborener Herzfehler, $<10 \mathrm{~kg}$ $n=162$

Studienziel

Hypothesentest: restriktive Strategie führt zu weniger Transfusionen bei vergleichbarer $\mathrm{O}_{2}$-Verfügbarkeit und ohne Auswirkung auf klinische Outcomes

Transfusionstrigger

$\mathrm{Hb} 7 \mathrm{~g} / \mathrm{dl}+$ klinische Indikation vs. 9,5 g/dl

$\mathrm{Hb} 9 \mathrm{~g} / \mathrm{dl}+$ klinische Indikation vs. $12 \mathrm{~g} / \mathrm{dl}$ bei palliativer Korrektur,

postoperativ

Ergebnisse

Keine signifikanten Unterschiede:

Klinische Outcomes: Mortalität, Thromboserate, cerebrovaskuläre Ereignisse, Intensivstation/Krankenhausaufenthalt, Notwendigkeit der extrakorporalen Membranoxygenierung (ECMO), Flüssigkeits- und Volumenbedarf, Laktatspiegel, arteriovenöse Sauerstoffgehaltsdifferenz

Kommentar

Transfusionsanteil in den Gruppen: $48 \%$ vs. $80 \%$ (Primäroutcome) $(p<0,001)$

Keine Angaben zu intraoperativen Transfusionen 
risiko erhöhen bzw. das Tumorwachstum beschleunigen könnten [114]. Tatsächlich wurde in Tierversuchen bestätigt, dass allogene Bluttransfusionen das Tumorwachstum beschleunigen und dieser Effekt auf das Vorhandensein von Leukozyten zurückgeführt werden kann. Durch eine (pre-storage) Leukozytendepletion der Präparate wurde der wachstumsfördernde Effekt vermieden [115].

Inwieweit neben den Leukozyten auch andere durch Transfusionen übertragene immunmodulierende Substanzen und Partikel (Phosphatidylserin-produzierende apoptotische Zellen, Zytokine, extrazelluläre Vesikel, Hämoglobin und freies Eisen, u. a.) für die Tumorentstehung bzw. das Tumorwachstum eine Rolle spielen können, ist derzeit nicht geklärt. Diskutiert wird u. a. ein möglicher Einfluss von Zytokinen (TNF- $\beta$ ) und VEGF (vascular endothelial growth factor) enthaltenden Mikropartikeln auf Tumorwachstum und Metastasierung [116].

Es gibt deshalb eine Vielzahl an Publikationen, die sich mit einem möglichen Zusammenhang zwischen Bluttransfusionen und dem Auftreten von Krebserkrankungen und vor allem mit dem Auftreten von Rezidiven bei den Transfusionsempfängern auseinandersetzen.

Für die Analyse einer möglichen Assoziation von Bluttransfusionen und Karzinogenese (Neogenese) kann aufgrund des erforderlichen langen Beobachtungszeitraumes und der hohen erforderlichen Fallzahlen nur auf Beobachtungsstudien zurückgegriffen werden. RCTs sind für diese Fragestellung nicht verfügbar.

Bei der Interpretation der Ergebnisse ist zu beachten, dass in zahlreichen Studien wegen des Studiendesigns mit großer Wahrscheinlichkeit ein „confounding by indication/indication bias" vorliegt, was zu systematisch verzerrten Ergebnissen (Effektschätzern) führen kann. EK werden zur Behandlung chronischer oder akuter Anämien eingesetzt. Die Anämie entsteht durch Bildungsstörungen, erhöhten Umsatz oder Blutverlust und ist damit Zeichen einer Vielzahl von medizinischen Konditionen. Eine Anämie kann im Zusammenhang mit Erkrankungen entstehen, die mit einer langen Latenzzeit mit Krebserkrankungen assoziiert sind (z.B.
Entstehung eines kolorektalen Karzinoms auf dem Boden einer Colitis ulcerosa).

Daneben werden auch direkt krebsassoziierte Anämien beobachtet, die wahrscheinlich durch eine komplexe Interaktion zwischen Tumorzellen und Immunsystem mit Ausschüttung inflammatorischer Zytokine und daraus resultierender Beeinträchtigung der Erythropoiese verursacht werden [117]. Im Rahmen des European Cancer Anaemia Survey wurde festgestellt, dass $30 \%$ der 4638 Patienten mit neudiagnostizierter Krebserkrankung bei Diagnosestellung anämisch waren [118].

Dass eine Abnahme der Hämoglobinkonzentration bereits mehrere Jahre vor der Krebsdiagnose beginnen kann, zeigte eine Auswertung von Daten der Scandinavian Donations and Transfusions (SCANDAT) Database. Edgren et al. konnten in einer retrospektiven Fall-Kontroll-Studie den Verlauf der Hämoglobinkonzentration bei 16.375 Personen mit neu diagnostizierter maligner Erkrankung mit den Verläufen bei 161.995 Personen ohne Krebsdiagnose vergleichen [119]. Die Autoren untersuchen den Zeitraum von 5 Jahren vor Diagnosestellung. Ein Abfall des Hämoglobinspiegels zeigte sich 3 Jahre vor Diagnose eines Magenkarzinoms, eines Multiplen Myeloms und einer lymphatischen Leukämie sowie zwei Jahre vor Diagnose eines Dünndarm-/Kolonkarzinoms und eines Hodgkin-Lymphoms. Der Hämoglobinspiegel sank im letzten Jahr vor Diagnosestellung eines non-Hodgkin-Lymphoms sowie einer myeloischen Leukämie. Unverändert blieb der Hämoglobinspiegel z. B. vor der Diagnose eines Mamma- und ProstataKarzinoms.

Eine Anämie - sofern sie nicht ausschließlich durch einen akuten, nicht krankheitsbedingten Blutverlust verursacht wird - kann somit ein Prädiktor für eine Krebserkrankung sein. Aus einem statistischen Zusammenhang zwischen EK-Transfusion, die zur Behandlung einer Anämie verabreicht wurde, und einer neu auftretenden Krebserkrankung kann daher keine Kausalität abgeleitet werden. Vielmehr deuten die Untersuchungsergebnisse darauf hin, dass Patienten mit nicht diagnostizierten subklinischen Tumorerkrankungen aufgrund einer krebs- assoziierten Anämie häufiger transfundiert werden (reverse causation).

\subsection{Ergebnisse aus \\ Beobachtungsstudien mit wahrscheinlichem „indication bias"}

Im Rahmen der bisher größten retrospektiven Fall-Kontroll-Studie zur Untersuchung eines möglichen Zusammenhangs von Bluttransfusionen und Krebsrisiko analysierten Riedl et al. Daten von 552.951 Patienten im Alter von $\geq 70$ Jahren mit Krebsdiagnose (solide Tumoren, Leukämien, Lymphome) im Vergleich zu 100.000 Kontrollpersonen [120]. Das Krebsrisiko war während der ersten 12 Monate nach einer Bluttransfusion signifikant erhöht (OR 2,05; 95 \% CI 1,95-2,16) und nahm dann deutlich ab. Das erhöhte Krebsrisiko betraf Karzinome des Magens, des Kolons, der Leber, der Niere, des Nierenbeckens, der Harnleiter, Lymphome, Myelome und Leukämien. Transfusionen in der Zeitspanne 13-30 Monate (OR 1,04; 95 \% CI 0,99-1,09) bzw. 31-48 Monate vor Diagnose (OR 1,05; 95 \% CI $1,00-1,11$ ) waren nicht mit einem insgesamt erhöhten Krebsrisiko assoziiert. Allerdings war das Risiko für Lebertumore auch bei Transfusion 13-30 Monate vor Diagnose signifikant erhöht. Bei Adjustierung des Modells für bekannte Risikofaktoren (u.a. chronische Lebererkrankung, Zirrhose, gastrointestinale Blutungen) wurde keine erhöhte OR ermittelt. Die Autoren diskutieren, dass die Risikoerhöhung bei solchen Krebserkrankungen beobachtet wurde, deren Vorerkrankungen oder Vorstufen mit intestinalen Blutungen oder Blutbildungsstörungen einhergehen können. Aufgrund der resultierenden Anämien werden diese Patienten wahrscheinlich vor der Krebsdiagnose häufiger transfundiert, was zu der signifikanten Assoziation zwischen einer Transfusion bis 12 Monate vor Diagnose und einer Krebserkrankung führen kann ( $r e$ verse causation).

Die Arbeitsgruppe von Hjalgrim et al. untersuchte Daten von 888.843 Transfusionsempfängern, bei denen zum Zeitpunkt der ersten Transfusion keine Krebserkrankung bekannt war [121]. In der Nachbeobachtungszeit zwischen 1968 und 2002 wurde bei 80.990 Personen eine Krebser- 
krankung diagnostiziert. Das standardisierte Inzidenzverhältnis (SIR) für Krebs (alle Diagnosen) betrug 5,36 (95\% CI 5,29-5,43) in den ersten 6 Monaten nach Transfusion. Auch hier argumentieren die Autoren, dass das Ergebnis am ehesten den erhöhten Transfusionsbedarf bei Vorliegen undiagnostizierter Krebserkrankungen widerspiegelt. Mehr als zwei Jahre nach Transfusion war das GesamtSIR nur noch $\leq 1,10$, allerdings blieb das Krebsrisiko nach Transfusion für Karzinome der Zunge, der Mundhöhle, des Pharynx, des Oesophagus, der Leber, des Respirationstrakts, des Harntrakts und für Plattenepithelkarzinome der Haut über einen Zeitraum von mehr als 10 Jahre erhöht. Für diese Krebserkrankungen gilt eine Assoziation zu den Risikofaktoren Rauchen und/oder Alkoholkonsum als gesichert. Basierend auf den Ergebnissen zu Prävalenzmustern dieser Risikofaktoren in der untersuchten Kohorte und für Tumorinzidenzen anderer Krankenhauspopulationen mit transfundierten und nichttransfundierten Patienten bewerten die Autoren das anhaltend höhere Risiko für diese Krebserkrankungen eher als Folge von Tabak- und Alkoholkonsum als von Transfusionen. Da Tabakund Alkoholgenuss auch Risikofaktoren für eine ganze Reihe anderer Erkrankungen sind, die zu Krankenhausaufenthalten und Transfusionen führen können, ist mit einer Assoziation zwischen Transfusionen und Tumorerkrankungen, die durch diese Lebensstilfaktoren verursacht/begünstigt werden, in allen Follow-up-Perioden zu rechnen.

Yang et al. untersuchten die Daten von 1,3 Mio. Frauen im medianen Alter von 56 Jahren, die 1998 im Rahmen eines Screening-Programms für Brustkrebs rekrutiert wurden [122]. 11.274 (0,9\%) Frauen erhielten eine Transfusion nach 2000. In der Gesamtkohorte wurde während des Follow-up bei 160.041 Frauen eine Krebserkrankung diagnostiziert, darunter 1648 bei transfundierten Personen. Die Inzidenz für Krebserkrankungen war in der Gruppe der transfundierten Frauen in den ersten 5 Jahren nach Transfusion signifikant erhöht. Die Autoren vermuteten einen Zusammenhang zwischen Krebsvorstufen und Transfusionsindikation. Nach $\geq 5$ Jahren blieb auch bei Ad- justierung für bekannte Risikofaktoren die Inzidenz für Leberkrebs ( $n=11$ Fälle) und non-Hodgkin Lymphome $(n=29$ Fälle) erhöht. Die Autoren diskutieren, dass das erhöhte Risiko für diese Tumore auf eine mögliche Übertragung onkogener Viren zurückgeführt werden könnte, auf die Blutpräparate nicht getestet wurden (z. B. Hepatitis G Virus, Epstein-BarrVirus).

Cerhan et al. analysierten die Daten von 37.337 Frauen der Iowa Women's Health Study Cohort [123]. Das Gesamtkrebsrisiko für eine Tumorerkrankung bei transfundierten Frauen war gegenüber nicht-transfundierten Frauen nach 12 Jahren nicht erhöht (RR 0,94; $95 \%$ CI 0,84-1,05). Signifikant erhöhte Risiken wurden allerdings für non-Hodgkin-Lymphome (RR 2,20; 95 \% CI 1,353,58 ) und Nierentumore (RR 2,53; $95 \%$ CI 1,34-4,78) ermittelt. Das Risiko für nonHodgkin-Lymphome war in den ersten 14 Jahren nach Transfusion erhöht, später fand sich kein signifikanter Zusammenhang mit einer Transfusion. Nierentumore traten erst $\geq 5$ Jahre nach Transfusion auf. Das Risiko blieb danach aber bis zu $\geq 30$ Jahre signifikant erhöht.

In einer Studie zur Untersuchung eines möglichen Zusammenhangs von Bluttransfusionen und Schilddrüsenkrebs fanden Fujino et al. in einer Kohorte von 37.983 Frauen keine signifikante Assoziation (RR 1,77; 95 \% CI 0,95-3,30) [124].

Im Rahmen einer größeren retrospektiven Fall-Kontroll-Studie mit 77.488 Patienten und 154.509 Kontrollen untersuchten Chang et al., ob die Transfusion von Erythrozytenkonzentraten einen Risikofaktor für maligne hämatologische Erkrankungen darstellt. Das Erkrankungsrisiko für hämatologische Neoplasien war nach Transfusion signifikant erhöht (OR 1,37; $95 \%$ CI 1,33-1,43) [125]. Das Risiko für myeloide Neoplasien nach Transfusion war dabei höher (OR 1,93; $95 \%$ CI 1,82-2,04) als für lymphoide Tumore (OR 1,21; 95 \% CI 1,16-1,26). Die Autoren schlossen zwar Fälle mit Transfusionen $<1$ Jahr vor Krebsdiagnose aus, um die Möglichkeit einer Transfusionsindikation aufgrund einer frühen undiagnostizierten Krebserkrankung zu minimieren, allerdings zeigte die Arbeit von Edgren et al. [119] eine recht deutliche Abnahme der
Hämoglobinkonzentration bei Patienten mit hämatologischen Neoplasien bereits 2 Jahre vor Diagnosestellung. Dies spiegelte sich auch in einer zeitlich stratifizierten Analyse wider, wo insbesondere bei den myeloiden Neoplasien die OR 1-2 Jahre nach Transfusion deutlich erhöht waren und anschließend deutlich abnahmen. Für die auch 10 Jahre nach Transfusion signifikant erhöhten OR für bestimmte hämatologische Krebserkrankungen kann nicht unmittelbar auf einen kausalen $\mathrm{Zu}$ sammenhang geschlossen werden, weil bei der Modelladjustierung weitere bekannte Risikofaktoren nicht berücksichtigt wurden.

Bei einer Analyse der Kohortendaten von 3177 Transfusionsempfängern und 29.910 hospitalisierten Patienten fanden Blomberg et al. nach einer Latenz von 3 Jahren und 6 Jahren Follow-up in der Kohorte der Transfusionsempfänger kein signifikant erhöhtes Gesamtkrebsrisiko (SMR 1,19; $95 \%$ CI 1,00-1,41), jedoch war die Inzidenz von Nierentumoren (SMR 2,65; $95 \%$ CI 1,21-5,03), nicht-melanotischem Hautkrebs (SMR 2,29; 95 \% CI 1,19-4,01) und malignen Lymphomen (SMR 2,70; $95 \%$ CI 1,44-4,62) signifikant erhöht [126]. In der Kohorte der hospitalisierten Patienten wurde für die transfundierten Personen ein signifikant erhöhtes Risiko für maligne Lymphome (IRR 3,11; $95 \%$ CI 1,56-6,20) und nicht-melanotischem Hautkrebs (IRR 2,74; 95 \% CI 1,25-6,00) ermittelt. Die Autoren argumentieren, dass durch die 3-jährige Latenz zwischen Transfusion und Follow-up ein möglicher Bias durch bereits vorliegende, noch unerkannte Krebsvorstufen minimiert ist. Allerdings blieben mögliche Confounder (Grunderkrankungen, Risikoexpositionen etc.) in der Analyse unberücksichtigt.

In einer japanischen Kohortenstudie mit 10.451 Teilnehmern und durchschnittlich ca. 13 Jahren Follow-up [127] wurde eine signifikante Assoziation zwischen selbstberichteter Transfusion und Krebsmortalität ermittelt (HR 1,75; $95 \%$ CI 1,32-2,33). Eine erhöhte Hazard Ratio fand sich für Leberkarzinome (HR 3,07; $95 \%$ CI 1,14-8,31), Bauchspeicheldrüsenkrebs (HR 3,34, $95 \%$ CI 1,28-8,72) und Tumore der Bauchhöhle (HR 1,99; $95 \%$ CI 1,01-3,91). Da in der Studie weder Daten zum Zeitpunkt der Transfusion noch 
Tab. 13 Studiencharakteristika und Ergebnisse von RCT zu Auswirkungen von EK-Transfusionen auf das Rezidivrisiko bei Tumorpatienten

\begin{tabular}{|c|c|c|c|c|}
\hline Studie & Setting & Intervention & Endpunkt & Ergebnis \\
\hline Busch 1993 [134] & $\begin{array}{l}\text { Kolorektales Karzinom } \\
(n=475)\end{array}$ & $\begin{array}{l}\text { Allogene versus } \\
\text { autologe Transfusion }\end{array}$ & $\begin{array}{l}\text { Krankheitsfreies Überleben, } \\
\text { Rezidivrate nach } 4 \text { Jahren }\end{array}$ & $\begin{array}{l}\text { Kein Unterschied zwischen } \\
\text { den Behandlungsgruppen }\end{array}$ \\
\hline Heiss 1994 [135] & $\begin{array}{l}\text { Kolorektales Karzinom } \\
(n=120)\end{array}$ & $\begin{array}{l}\text { Allogene versus } \\
\text { autologe Transfusion }\end{array}$ & $\begin{array}{l}\text { Rezidivrate; mediane Nachbe- } \\
\text { obachtungszeit } 22 \text { Monate }\end{array}$ & $\begin{array}{l}\text { Unterschied zwischen den } \\
\text { Behandlungsgruppen nicht } \\
\text { signifikant }\end{array}$ \\
\hline Harlaar 2012 [136] & $\begin{array}{l}\text { Langzeit-Ergebnisse der } \\
\text { Studie Busch } 1993\end{array}$ & $\begin{array}{l}\text { Allogene versus } \\
\text { autologe Transfusion }\end{array}$ & $\begin{array}{l}\text { 20-Jahres Überleben, krebs- } \\
\text { spezifisches Überleben nach } \\
10 \text { Jahren }\end{array}$ & $\begin{array}{l}\text { Besseres Überleben und } \\
\text { besseres krebsspezifisches } \\
\text { Überleben in der allogen } \\
\text { transfundierten Gruppe }\end{array}$ \\
\hline
\end{tabular}

zum Zeitpunkt der Krebsdiagnose vorlagen, kann ein relevanter „indication bias“ nicht ausgeschlossen werden.

Aufgrund der bekannten Assoziation zwischen Immundefizienz (u. a. Autoimmunerkrankung, immunsuppressive Therapie, HIV-Infektion) und non-HodgkinLymphom (NHL) wurde ein möglicher Zusammenhang zwischen Transfusionen und NHL in der Literatur intensiv diskutiert. Castillo et al. haben dazu in einer Metaanalyse 14 Studien ausgewertet [128]. Das Erkrankungsrisiko nach Transfusion war insgesamt signifikant erhöht (RR 1,20; 95 \% CI 1,07-1,35) und unabhängig vom Zeitpunkt der Transfusion (vor/nach 1992) und damit wahrscheinlich unabhängig von der Einführung der Leukozytendepletion. Studien mit hoher Wahrscheinlichkeit eines „indication bias" wurden von der Metaanalyse nicht ausgeschlossen. Im Großteil der eingeschlossenen Studien wurden bekannte Risikofaktoren für NHL wie Autoimmunerkrankungen oder immunsuppressive Therapien als mögliche Confounder nicht berücksichtigt.

In einer gepoolten Analyse von 20 Fall-Kontroll-Studien im Rahmen des InterLymph Consortium mit 17.471 NHLFällen und 23.096 Kontrollen wurden mögliche medizinische, lebensstilassoziierte, familiäre und berufliche Risikofaktoren für ein NHL untersucht [129]. Bluttransfusionen nach 1990 stellten in dieser Analyse keinen Risikofaktor dar (OR 0,76; $95 \%$ CI 0,67-0,87).

\subsection{Ergebnisse aus Beobachtungsstudien in Kohorten mit sehr geringer Wahrscheinlichkeit für einen "indication bias"}

Memon et al. analysierten die Daten einer Kohorte von 12.329 Neugeborenen, die in den Jahren 1942-1970 entweder kurz nach ihrer Geburt Austauschtransfusionen oder in Einzelfällen intrauterine Transfusionen zur Behandlung einer hämolytischen Erkrankung erhielten [130]. Weder in der Gruppe der 1-14 Jährigen (RR 1,03; $95 \%$ CI 0,59-1,68) noch in der Gruppe der 15-49 Jährigen war das Risiko für Neoplasien (RR 1,14; 95 \% CI 0,911,42) signifikant erhöht.

Anderson et al. untersuchten in einer prospektiven Kohorte von entbindenden Frauen mit Blutungskomplikationen unter der Geburt die Inzidenz maligner Tumore sowie einen möglichen Zusammenhang zwischen Transfusion und malignen Lymphomen in einer eingebetteten FallKontroll-Studie [131]. Die Häufigkeit maligner Tumore in der Kohorte, in der ca. ein Viertel der Frauen transfundiert wurde, unterschied sich nicht von der entsprechenden erwarteten Häufigkeit in der Allgemeinbevölkerung (standardized morbidity ratio 0,$95 ; 95 \%$ CI 0,89-1,01). Die Fall-Kontroll-Studie ergab keinen Hinweis auf eine Assoziation zwischen Transfusionen und malignen Lymphomen. Für Morbus Hodgkin wurde eine OR von 1,4 (95\% CI 0,3-7,6) ermittelt. Keine der Frauen mit NHL wurde transfundiert $(\mathrm{OR}=0)$.

Ein ähnliches Studiendesign wählten Skånberg und Frisk [132], die in einer retrospektiven Kohorte die Daten von 14.114 entbundenen Frauen analysierten. In ei- ner eingebetteten Fall-Kontroll-Studie wurden 621 Frauen mit Transfusion unter der Geburt und 1216 Frauen ohne Transfusion verglichen. Es fand sich kein $\mathrm{Zu}-$ sammenhang zwischen Transfusion und Häufigkeit maligner Erkrankungen (RR 1,04; $95 \%$ CI 0,69-1,53). Es wurde kein Unterschied beim krebsfreien Überleben über einen Zeitraum von 32 Jahren nach Entbindung beobachtet.

\subsection{Zusammenfassung}

Der Großteil der Beobachtungsstudien zur Untersuchung eines möglichen Zusammenhanges zwischen Bluttransfusionen und Neoplasien wurde in Patientenpopulationen durchgeführt, in denen ein „indication bias" wahrscheinlich relevant war. Darauf deuten die ermittelten höheren Risiken für Krebserkrankungen in den ersten zwei Jahren nach Transfusion, die anschließend deutlich abnahmen. Für einige Krebsentitäten wurden erhöhte transfusionsassoziierte Langzeitrisiken beschrieben. Es ist unklar, ob Bluttransfusionen zur Karzinogenese beitragen, da relevante Confounder (z. B. lebensstilassoziierte Risikofaktoren, Grunderkrankungen) nur in Einzelfällen berücksichtigt wurden. Eine Studie mit entsprechender Modelladjustierung diskutiert ein möglicherweise durch die Übertragung onkogener Viren erhöhtes Risiko für Leberkrebs und NHL.

In Studien, bei denen ein „indication bias" nahezu ausgeschlossen werden konnte, wurde kein erhöhtes Krebsrisiko bei den Transfundierten beobachtet. 


\section{Einfluss von Transfusionen mit Erythrozytenkonzentraten auf das Rezidivrisiko von Krebspatientinnen und -patienten}

\subsection{Randomisiert-kontrollierte Studien}

Im Gegensatz zu den Untersuchungen eines möglichen Zusammenhangs zwischen EK-Transfusionen und Kanzerogenese (Primärtumor) wurden zur Untersuchung des transfusionsassoziierten Rezidivrisikos mehrere RCTs durchgeführt. Zwei RCTs verglichen jeweils die Auswirkungen von allogenen und autologen Transfusionen, da Studien im Tiermodell gezeigt hatten, dass autologe Transfusionen im Gegenteil zu allogenen Transfusionen das Tumorwachstum nicht förderten (z. B. [133]; - Tab. 13).

Keine der bisher publizierten prospektiv randomisierten Studien, die allogene und autologe Transfusionen im Rahmen der chirurgischen Krebstherapie untersuchten, zeigte eine Überlegenheit einer autologen Transfusionsstrategie hinsichtlich der Rezidivrate bzw. dem rezidivfreien Überleben.

\subsection{Beobachtungsstudien}

Ein möglicher kausaler Zusammenhang zwischen dem Rezidivrisiko von Krebspatienten und der Gabe von Bluttransfusionen im Rahmen der operativen Therapie des Primärtumors wurde auch in einer Reihe von Beobachtungsstudien für verschiedene Krebsarten untersucht, insbesondere bei Darmkrebs, Harnblasenkrebs und dem Leberzellkarzinom (• Tab. 14). Außerdem liegen mehrere Metaanalysen zur genannten Thematik vor.

Ähnlich wie bei den Studien zum Neuauftreten von Krebserkrankungen nach Transfusion ist das Problem des „confounding by indication" zu beachten. Eine fortgeschrittene Krebserkrankung geht in der Regel mit einer umfangreicheren Operation, damit auch höheren Blutverlusten und einer höheren Wahrscheinlichkeit einer Transfusion einher. Gleichzeitig ist aber ein höheres Tumorstadium in aller Regel auch mit einem höheren Rezidivrisiko verknüpft [137]. Das Tumorstadium wäre demnach als klassischer Confounder zu werten, der einen statistischen Zusammenhang zwischen Transfusionsgabe und Rezidivrisiko erzeugen kann, auch wenn kein kausaler Zusammenhang vorliegt.

Aus diesem Grund erscheinen grundsätzlich nur Beobachtungsstudien aussagekräftig, bei denen der Schätzer für das Rezidivrisiko von transfundierten im Vergleich zu nicht-transfundierten Patienten zumindest für das Tumorstadium adjustiert wurde. Grundsätzlich sind auch andere Confounder denkbar. Dies gilt vor allem für Studien, die das Rezidivrisiko nur im Rahmen eines kombinierten Endpunktes (rezidivfreies Überleben) untersucht haben. Hier könnten vor allem Begleiterkrankungen sowohl die Wahrscheinlichkeit für eine Transfusion (über einen erniedrigten präoperativen $\mathrm{Hb}$-Wert) als auch für die Überlebenschancen und damit auch das rezidivfreie Überleben beeinflussen und wären als potentieller Confounder zu berücksichtigen. Begleiterkrankungen, die das Immunsystem beeinflussen, könnten theoretisch das Rezidivrisiko auch direkt beeinflussen. Denkbar wäre außerdem, dass Patienten mit Begleiterkrankungen aufgrund einer weniger intensiven Therapie (aufgrund von Kontraindikationen) ein erhöhtes Rezidivrisiko haben. Eine valide Adjustierung für Begleiterkrankungen ist aufgrund der meist fehlenden standardisierten Erfassung und adäquaten Bewertung der Krankheitsschwere schwierig. Die ungenaue Erfassung einer Confounding-Variable führt in der Regel dazu, dass der Einfluss des Confounders unterschätzt und damit der Einfluss der unabhängigen Variable (hier: Transfusion) tendenziell überschätzt wird.

Kritisch anzumerken ist, dass die Auswahl der in die Modelle zur Berechnung von Risikoschätzern eingehenden Variablen/Confounder nicht immer gut durchdacht erscheint und sich häufig eher an den vorhandenen Daten als an einem theoretisch gut fundierten Modell orientiert. Außerdem ist $\mathrm{zu}$ berücksichtigen, dass grundsätzlich immer die Gefahr besteht, dass wirksame Confounder nicht oder nicht adäquat erfasst werden („residual confounding"). Somit sind weder statistisch signifikante Ergebnisse in multivariaten Analysen als Beweis für einen kausalen Zusammenhang anzusehen, noch lässt sich aus einem nicht-signifikanten Ergebnis auf das Fehlen eines solchen schließen. Bei weitgehendem Fehlen klinisch-randomisierter Interventionsstudien ist es dennoch unerlässlich, bei der Bewertung der Evidenz auf Beobachtungsstudien zurückzugreifen. Vor allem die Konsistenz und Reproduzierbarkeit von Ergebnissen als auch die Stärke der beobachtenden Effekte sind, bei grundsätzlich gegebener biologischer Plausibilität, als Bewertungskriterien heranzuziehen.

\subsubsection{Bewertung der vorliegenden Studien - Metanalysen}

Alle vorliegenden Metaanalysen zeigen einen statischen Zusammenhang zwischen der Gabe einer oder mehrerer Bluttransfusionen im Rahmen der operativen Therapie der Krebserkrankung und dem Gesamtüberleben, dem krebsspezifischen und rezidivfreien Überleben und des Rezidivrisikos. Allerdings beruhen alle diese Ergebnisse auf nicht-adjustierten Risikoschätzern der einzelnen Studien. Aufgrund der unterschiedlichen Modellierungen wurde in keinem Fall eine multivariate Analyse der gepoolten Daten durchgeführt, so dass selbst wahrscheinliche Confounder wie das Tumorstadium in den Ergebnissen der Metaanalysen nicht berücksichtigt sind.

\subsubsection{Bewertung der vorliegenden Studien - Einzelstudien}

In - Tab. 14 ist eine Auswahl an Studien aufgeführt, in denen der Endpunkt Rezidiv oder der kombinierte Endpunkt rezidivfreies Überleben untersucht und in einer multivariablen Analyse mit mindestens einer Adjustierung nach Tumorstadium ein Risikoschätzer ermittelt wurde.

In der Mehrzahl der aufgeführten Studien wurde versucht, das Problem des „confounding by indication" durch Adjustierung des präoperativen HämoglobinWerts zu minimieren. Einzelne Studien berücksichtigen stattdessen den intraoperativen Blutverlust, eine Studie nahm beide Variablen mit ins Modell auf, in anderen Studien wurde keine der beiden Variablen berücksichtigt.

In den Studien zum Rezidivrisiko nach Darmkrebs zeigte sich kein konsistentes Ergebnis für einen Einfluss von perioperativen Transfusionen. Die Studie von Edna et al. berichtet eine signifikant erhöhte 
Tab. 14 Studiencharakteristika und Ergebnisse von Beobachtungsstudien zu Auswirkungen von EK-Transfusionen auf das Rezidivrisiko bei

verschiedenen Tumorarten

Kolorektales Karzinom (CRC)

Studie(n)

Donohue 1995 [138]

Patientenkollektiv

(transfundiert vs. nicht-trans-

CRC, kurative Resektion,

fundiert)

$n=1051$

Adjustierung

(446 vs. 605)

Ergebnisse (adj.)

Tumorstadium (Stage III vs. II)

Kein signifikanter Unterschied:

Rezidivrisiko, Gesamtmortalität

Kommentar

Studie(n)

Edna 1998 [139]

Patientenkollektiv

(transfundiert vs. nicht-trans-

fundiert)

CRC, kurative Resektion

$n=336$

(236 vs. 100)

Adjustierung

Ergebnisse (adj.)

Tumorstadium

Signifikanter Unterschied:

Höheres Rezidivrisiko und geringeres tumorspezifisches Überleben bei > 2 EK

Kein signifikanter Unterschied:

Rezidivrisiko, Tumorspezifisches Überleben bei 1-2 EK

Kommentar

Studie(n)

Jagoditsch 2006 [140]

Patientenkollektiv

(transfundiert vs. nicht-trans-

fundiert)

Rektaltumor

$n=597$

Adjustierung

(471 vs. 126; inkl. 104 autologe Transfusionen)

Tumorstadium

Ergebnisse (adj.)

Kein signifikanter Unterschied:

Rezidivfreies Überleben, Metastasen-freies Überleben, Gesamtmortalität

Kommentar Kein Unterschied zwischen allogenen und autologen Transfusionen, kein Dosiseffekt (1-3 EK vs. >3 EK)

Studie(n)

Talukder 2014 [141]

Patientenkollektiv

(transfundiert vs. nicht-trans-

CRC, kurative Resektion

fundiert)

$n=1370$

(423 vs. 947)

Adjustierung

Ergebnisse (adj.)

Tumorstadium, präoperative Anämie

Signifikanter Unterschied:

Höheres Rezidivrisiko bei intraoperativer, perioperativer bzw. postoperativer Transfusion

Höhere tumorspezifische Mortalität und Gesamtmortalität bei intraoperativer Transfusion

Kein signifikanter Unterschied:

Tumorspezifische Mortalität und Gesamtmortalität bei perioperativen bzw. postoperativen Transfusionen

Kommentar -

Studie(n) Warschkow 2014 [142]

\begin{tabular}{ll}
$\begin{array}{l}\text { Patientenkollektiv } \\
\text { (transfundiert vs. nicht-trans- } \\
\text { fundiert) }\end{array}$ & $\begin{array}{l}\text { Rektalkarzinom, kurative Resektion } \\
n=401 \\
(217 \text { vs. 184) }\end{array}$ \\
$\begin{array}{l}\text { Adjustierung } \\
\text { Ergebnisse (adj.) }\end{array}$ & $\begin{array}{l}\text { Tumorstadium, präoperativer Hb, intra } \\
\text { Kein signifikanter Unterschied: } \\
\text { Rezidivrisiko, Gesamtmortalität }\end{array}$ \\
Kommentar & Propensity score matching \\
Studie(n) & Mörner 2017 [143] \\
\hline $\begin{array}{l}\text { Patientenkollektiv } \\
\text { (transfundiert vs. nicht-trans- } \\
\text { fundiert) }\end{array}$ & $\begin{array}{l}\text { CRC, kurative Resektion } \\
n=496\end{array}$ \\
Adjustierung & (199 vs. 297) \\
\hline
\end{tabular}




\section{Tab. 14 (Fortsetzung)}

Ergebnisse (adj.)

Rezidivrisiko, Gesamtmortalität

Kommentar

Präoperative Anämie im adjustierten Modell signifikant mit erhöhtem Rezidiv- und Mortalitätsrisiko assoziiert

Studie(n)

Amri 2017 [144]

Patientenkollektiv

(transfundiert vs. nicht-trans-

fundiert)

Kolontumor, primäre Resektion

$n=1423$

(305 vs. 1118)

Adjustierung

Ergebnisse (adj.)

Tumorstadium

Signifikanter Unterschied:

Höhere Gesamtmortalität nach Transfusion

Kein signifikanter Unterschied:

Rezidivrisiko, Metastasierungsrisiko, tumorspezifische Mortalität

Kommentar

Studie(n)

Hu 2018 [145]

Patientenkollektiv

(transfundiert vs. nicht-trans-

fundiert)

CRC, primäre Resektion

$n=4030$

(1010 vs. 3020)

Adjustierung

Tumorstadium, präoperative Anämie

Ergebnisse (adj.)

Kommentar

\section{Signifikanter Unterschied:}

Geringeres rezidivfreies und Gesamt-Überleben nach Transfusion

Vergleichbare Ergebnisse nach propensity score-Matching;

Kein Dosiseffekt ( $\leq 4$ vs. >4 EK) beim rezidivfreiem Überleben

Hepatozelluläres Karzinom (HCC)

Studie(n)

Choi 2009 [146]

Patientenkollektiv

HBV-assoziiertes HCC, kurative Resektion

(transfundiert vs. nicht-trans-

fundiert)

$n=190$

(94 vs. 96)

Adjustierung

Tumorstadium

Ergebnisse (adj.)

Signifikanter Unterschied:

Geringeres rezidivfreies Überleben nach perioperativer Transfusion

Kein signifikanter Unterschied:

Gesamtmortalität

Kommentar

Transfusionseinfluss nur bei frühen intrahepatische Rezidive ( $<14$ Monate nach Resektion)

Studie(n)

Wang 2009 [147]

Patientenkollektiv

(transfundiert vs. nicht-trans-

fundiert)

HCC, Hepatektomie

$n=473$

(62 vs. 411)

Adjustierung

Tumorgröße

Ergebnisse (adj.)

Signifikanter Unterschied:

Geringeres rezidivfreies und Gesamt-Überleben nach Transfusion

Kommentar

Studie(n)

Harada 2015 [148]

Patientenkollektiv

(transfundiert vs. nicht-trans-

fundiert)

HCC, Child-Pugh A, Kurative Hepatektomie

$n=479$

(91 vs. 388)

Adjustierung

Ergebnisse (adj.)

Tumorstadium, intraoperativer Blutverlust

Signifikanter Unterschied:

Geringeres rezidivfreies und Gesamt-Überleben nach Transfusion

Kommentar $-$ 


\section{Tab. 14 (Fortsetzung)}

\begin{tabular}{|c|c|}
\hline Studie(n) & Yang 2016 [149] \\
\hline $\begin{array}{l}\text { Patientenkollektiv } \\
\text { (transfundiert vs. nicht-trans- } \\
\text { fundiert) }\end{array}$ & $\begin{array}{l}\text { HCC, Kurative Hepatektomie } \\
n=1103 \\
\text { (285 vs. } 818 \text { ) } \\
\text { Propensity score-Matching } \\
\text { (234 vs. } 234 \text { ) }\end{array}$ \\
\hline Adjustierung & Tumorstadium, präoperative Anämie beim Matching berücksichtigt \\
\hline Ergebnisse (adj.) & $\begin{array}{l}\text { Signifikanter Unterschied: } \\
\text { Geringeres rezidivfreies und Gesamt-Überleben nach Transfusion in Gesamtkohorte } \\
\text { Kein signifikanter Unterschied: } \\
\text { Rezidivfreies Überleben, Gesamtmortalität in Propensity score-Analyse }\end{array}$ \\
\hline Kommentar & $\begin{array}{l}\text { Autoren schlussfolgern, dass bei Berücksichtigung relevanter Einflussfaktoren (Matching) Transfusionen keinen } \\
\text { Einfluss auf rezidivfreies und Gesamt-Überleben haben }\end{array}$ \\
\hline \multicolumn{2}{|l|}{ Harnblasenkrebs } \\
\hline Studie(n) & Lindner 2013 [150] \\
\hline $\begin{array}{l}\text { Patientenkollektiv } \\
\text { (transfundiert vs. nicht-trans- } \\
\text { fundiert) }\end{array}$ & $\begin{array}{l}\text { Harnblasenkrebs, radikale Zystektomie } \\
n=2060 \\
(1279 \text { vs. } 781)\end{array}$ \\
\hline Adjustierung & Tumorstatus, präoperativer $\mathrm{Hb}$ \\
\hline Ergebnisse (adj.) & $\begin{array}{l}\text { Signifikanter Unterschied: } \\
\text { Höheres Rezidivrisiko, höhere tumorspezifische und Gesamt-Mortalität nach Transfusion }\end{array}$ \\
\hline Kommentar & - \\
\hline Studie(n) & Abel 2014 [151] \\
\hline $\begin{array}{l}\text { Patientenkollektiv } \\
\text { (transfundiert vs. nicht-trans- } \\
\text { fundiert) }\end{array}$ & $\begin{array}{l}\text { Harnblasenkrebs, radikale Zystektomie ohne Begleitchemotherapie } \\
n=360 \\
\text { (241 vs. } 119) \\
\text { Evaluationskohorte } \\
n=1770 \\
(1100 \text { vs. } 670)\end{array}$ \\
\hline Adjustierung & Tumorstatus, Präoperativer $\mathrm{Hb}$ \\
\hline Ergebnisse (adj.) & $\begin{array}{l}\text { Signifikanter Unterschied: } \\
\text { Höhere tumorspezifische Mortalität nach intraoperativer Transfusion in Studienkohorte } \\
\text { Höheres Rezidivrisiko, höhere tumorspezifische und Gesamt-Mortalität nach intraoperativer Transfusion in Evaluati- } \\
\text { onskohorte } \\
\text { Kein signifikanter Unterschied: } \\
\text { Rezidivrisiko, tumorspezifische und Gesamt-Mortalität nach postoperativer Transfusion in beiden Kohorten; } \\
\text { Rezidivrisiko und Gesamtmortalität nach intraoperativer Transfusion in Studienkohorte }\end{array}$ \\
\hline Kommentar & Re-Analyse der Daten von Lindner 2013 \\
\hline Studie(n) & Kluth 2014 [152] \\
\hline $\begin{array}{l}\text { Patientenkollektiv } \\
\text { (transfundiert vs. nicht-trans- } \\
\text { fundiert) }\end{array}$ & $\begin{array}{l}\text { Harnblasenkrebs, radikale Zystektomie } \\
n=2895 \\
(1128 \text { vs. } 1767)\end{array}$ \\
\hline Adjustierung & Tumorstatus \\
\hline Ergebnisse (adj.) & $\begin{array}{l}\text { Kein signifikanter Unterschied: } \\
\text { Rezidivrisiko, tumorspezifische und Gesamt-Mortalität nach Transfusion }\end{array}$ \\
\hline Kommentar & - \\
\hline
\end{tabular}




\section{Tab. 14 (Fortsetzung)}

\begin{tabular}{|c|c|}
\hline Studie(n) & Moschini 2015 [153] \\
\hline $\begin{array}{l}\text { Patientenkollektiv } \\
\text { (transfundiert vs. nicht-trans- } \\
\text { fundiert) }\end{array}$ & $\begin{array}{l}\text { Harnblasenkrebs, radikale Zystektomie } \\
n=1490 \\
(580 \text { vs. } 910)\end{array}$ \\
\hline Adjustierung & Tumorstatus \\
\hline Ergebnisse (adj.) & $\begin{array}{l}\text { Signifikanter Unterschied: } \\
\text { Höheres Rezidivrisiko, höhere tumorspezifische und Gesamt-Mortalität nach intraoperativer Transfusion } \\
\text { Kein signifikanter Unterschied: } \\
\text { Rezidivrisiko, tumorspezifische und Gesamt-Mortalität nach postoperativer Transfusion }\end{array}$ \\
\hline Kommentar & - \\
\hline Studie(n) & Vetterlein 2018 [154] \\
\hline $\begin{array}{l}\text { Patientenkollektiv } \\
\text { (transfundiert vs. nicht-trans- } \\
\text { fundiert) }\end{array}$ & $\begin{array}{l}\text { Harnblasenkrebs, radikale Zystektomie } \\
n=611 \\
(315 \text { vs. 296) }\end{array}$ \\
\hline Adjustierung & Tumorstatus, Blutverlust \\
\hline Ergebnisse (adj.) & $\begin{array}{l}\text { Kein signifikanter Unterschied: } \\
\text { Rezidivrisiko, tumorspezifische und Gesamt-Mortalität nach Transfusion }\end{array}$ \\
\hline Kommentar & - \\
\hline \multicolumn{2}{|l|}{ Andere Karzinome } \\
\hline Studie(n) & Uccella 2013 [155] \\
\hline $\begin{array}{l}\text { Patientenkollektiv } \\
\text { (transfundiert vs. nicht-trans- } \\
\text { fundiert) }\end{array}$ & $\begin{array}{l}\text { Uteruskarzinom, Hysterektomie } \\
N=358 \\
\text { (27 vs. } 331 \text { ) }\end{array}$ \\
\hline Adjustierung & Tumorstatus, präoperative Anämie \\
\hline Ergebnisse (adj.) & $\begin{array}{l}\text { Signifikanter Unterschied: } \\
\text { Höheres Rezidivrisiko nach Transfusion }\end{array}$ \\
\hline Kommentar & - \\
\hline Studie(n) & Lopez-Aguiar 2018 [156] \\
\hline $\begin{array}{l}\text { Patientenkollektiv } \\
\text { (transfundiert vs. nicht-trans- } \\
\text { fundiert) }\end{array}$ & $\begin{array}{l}\text { Gallenblasenkarzinom, kurative radikale Cholezystektomie } \\
n=262 \\
\text { (61 vs. 201) }\end{array}$ \\
\hline Adjustierung & Tumorstadium \\
\hline Ergebnisse (adj.) & $\begin{array}{l}\text { Signifikanter Unterschied: } \\
\text { Höhere tumorspezifische und Gesamt-Mortalität nach Transfusion }\end{array}$ \\
\hline Kommentar & - \\
\hline Studie(n) & Abu-Ghanem 2019 [157] \\
\hline $\begin{array}{l}\text { Patientenkollektiv } \\
\text { (transfundiert vs. nicht-trans- } \\
\text { fundiert) }\end{array}$ & $\begin{array}{l}\text { Nierenzellkarzinom, partielle od. radikale Nephrektomie } \\
N=1168 \\
\text { ( } 970 \text { vs. 198) }\end{array}$ \\
\hline Adjustierung & Tumorstadium, präoperativer $\mathrm{Hb}$ \\
\hline Ergebnisse (adj.) & $\begin{array}{l}\text { Signifikanter Unterschied: } \\
\text { Rezidivrisiko, tumorspezifische und Gesamt-Mortalität höher nach intraoperativer Transfusion } \\
\text { Höhere Gesamt-Mortalität nach postoperativer Transfusion } \\
\text { Kein signifikanter Unterschied: } \\
\text { Rezidivrisiko und tumorspezifische Mortalität nach postoperativer Transfusion }\end{array}$ \\
\hline Kommentar & - \\
\hline
\end{tabular}

krebsspezifische Mortalität nach Transfusion von $\geq 2$ EK [139]. Auch Hu et al. fanden in einer großen Kohortenstudie mit mehr als 4000 Patienten sowohl im adjustierten Modell als auch in einer Propensi-
ty-Score-Analyse signifikant erhöhte Hazard Ratios für das Rezidivrisiko, jedoch keinen Dosiseffekt [145]. In der Studie von Talkuder et al. war das adjustierte Rezidivrisiko ebenfalls erhöht [141].
Dagegen zeigten mehrere Studien entweder keinen Einfluss von Transfusionen auf das Rezidivrisiko bei kolorektalen Tumoren [138, 140, 143, 144] oder ein in der univariablen Analyse gezeigter 
Zusammenhang fand sich nach Adjustierung und in einer Propensity Score-Analyse nicht bestätigt [142].

Bei den Studien zum Harnblasenkrebs zeigte sich kein generell erhöhtes Rezidivrisiko durch EK-Transfusionen. In den Studien von Abel [151] (2 Kohorten), Kluth [152] und Vetterlein [154] wurde in der multivariablen Analyse mit Adjustierung für Tumorspezifika kein signifikant erhöhtes Rezidivrisiko ermittelt. Die von Lindner et al. in einer Studie mit $>2000$ Patienten beobachtete statistisch signifikante Risikoerhöhung für Rezidive von $20 \%$ [150] wurde bei nachträglicher Adjustierung für den intraoperativen Blutverlust nicht bestätigt (HR 1,14; $95 \%$ CI 0,94-1,37; [158]).

Für das Leberzellkarzinom zeigte der Großteil der Studien einen signifikanten Effekt. Die Studie von Yang et al., in der eine Propensity Score-Analyse in einer Subpopulation durchgeführt wurde, zeigte, dass bei entsprechendem Matching der Patienten der vorab ermittelte signifikante Effekt von Transfusionen auf das rezidivfreie Überleben nicht mehr vorhanden war und ebenso kein Unterschied in den Rezidivraten bestand [149].

Insgesamt waren die ermittelten relativen Risiken tendenziell etwas höher, wenn statt des primären Endpunkts „Rezidiv“ der Endpunkt „Tod“ bzw. „krebsbedingter Sterbefall“ oder ein kombinierter Endpunkt („Tod oder Rezidiv“) betrachtet wurde. Der Großteil der Studien zeigte einen statistisch signifikanten Zusammenhang zwischen Transfusionsereignissen und den genannten Endpunkten. Das Überleben nach Krebs scheint also statistisch stärker mit der Exposition einer durchgeführten Transfusion zusammenzuhängen als das Rezidivereignis. Ein "residual confounding“ z.B. durch Begleiterkrankungen wäre eine mögliche Erklärung: Tumorpatientinnen und -patienten mit Begleiterkrankungen erhalten eher eine Transfusion und haben gleichzeitig ein schlechteres Überleben als solche ohne Begleiterkrankungen.

In einigen Studien wurde in stratifizierten Analysen der Transfusionszeitpunkt genauer beleuchtet. Hier zeigte sich in mehreren Studien, dass intraoperative Transfusionen das Rezidivrisiko bzw. die krebsspezifische Mortalität im Gegensatz zu postoperativen Transfusionen signifikant erhöhten [151, 153, 157]. Operative Komplikationen bzw. Tumorcharakteristi$\mathrm{ka}$, die zu einem erhöhten Blutverlust führen, scheinen deshalb eher in Zusammenhang mit dem Rezidivrisiko zu stehen als die Transfusionen per se. Dies wurde auch in einer Untersuchung von Ito et al. mit nicht-transfundierten Patienten gezeigt, in der der intraoperationale Blutverlust als unabhängiger Prädiktor für das Rezidivrisiko ermittelt wurde [159].

\subsection{Zusammenfassung}

Die Beobachtungsstudien ergeben bisher aufgrund methodischer Limitationen, aber auch aufgrund nicht-konsistenter Ergebnisse keine überzeugenden Hinweise für einen kausalen Zusammenhang zwischen Transfusion von Blutprodukten im Zusammenhang mit operativer Therapie bösartiger Tumore und Rezidivrisiko. Randomisiert-kontrollierte Studien, die Transfusionen mit autologen vs. allogenen EK untersuchten, zeigten keinen signifikanten Unterschied bei den Rezidivraten. Es fehlen nach unserer Kenntnis bisher Ergebnisse aus randomisierten Studien, die spezifisch das Rezidivrisiko von Krebspatienten nach einer liberaleren oder restriktiven Transfusionsstrategie untersucht haben. Nur mit solchen Untersuchungen ließe sich letztlich klären, ob ein klinisch relevanter, kausaler Effekt vorliegt. Hier besteht Forschungsbedarf.

Grundsätzlich muss man davon ausgehen, dass der Evidenzgrad der Beobachtungsstudien zur genannten Fragestellung als verhältnismäßig gering anzusehen ist und eher der Generierung als der Bestätigung von Hypothesen dient. Dazu trägt unter anderem bei, dass viele Studien retrospektiv angelegt sind und in der Regel keine Fallzahl- bzw. Powerberechnungen durchgeführt wurden. Einige der Studien wären aufgrund der Studiengröße gar nicht in der Lage gewesen, einen kleinen, aber klinisch relevanten Effekt statistisch nachzuweisen.

Für den Arbeitskreis Blut

Dr. Ruth Offergeld

Vorsitzende
Die Stellungnahme und die wissenschaftlichen Erläuterungen wurden erarbeitet von der Untergruppe „TRIM“ des AK Blut: Prof. Dr. von Heymann (Federführung), Prof. Dr. Beckhove, Prof. Dr. Bein, Prof. Dr. Bornhäuser, Prof. Dr. Dame, Dr. Kraywinkel, Dr. Offergeld, Prof. Dr. Peter, Dr. Preußel, PD Dr. Ziemann.

\section{Literatur}

1. Bernard AC, Davenport DL, Chang PK, Vaughan TB, Zwischenberger JB (2009) Intraoperative transfusion of $1 \mathrm{U}$ to $2 \mathrm{U}$ packed red blood cells is associated with increased 30-day mortality, surgical-site infection, pneumonia, and sepsis in general surgery patients. J Am Coll Surg 208:931-937

2. Glance LG, Dick AW, Mukamel DB, Fleming FJ, Zollo RA, Wissler R, Salloum R, Meredith UW, Osler TM (2011) Association between intraoperative blood transfusion and mortality and morbidity in patients undergoing noncardiac surgery. Anesthesiology 114:283-292

3. Remy KE, Hall MW, Cholette J, Juffermans NP, Nicol K, Doctor A, Blumberg N, Spinella PC, Norris PJ, Dahmer MK, Muszynski JA (2018) Mechanisms of red blood cell transfusion-related immunomodulation. Transfusion 58:804-815

4. Youssef LA, Spitalnik SL (2017) Transfusionrelated immunomodulation: a reappraisal. Curr Opin Hematol 24:551-557

5. Baumgartner JM, Nydam TL, Clarke JH, Banerjee A, Silliman CC, McCarter MD (2009) Red blood cell supernatant potentiates LPS-induced proinflammatory cytokine response from peripheral blood mononuclear cells. J Interferon Cytokine Res 29:333-338

6. Hart S, Cserti-Gazdewich CM, McCluskey SA (2015) Red cell transfusion and the immune system. Anaesthesia 70(Suppl 1: 38-45):e13-36

7. Sparrow RL (2010) Red blood cell storage and transfusion-related immunomodulation. Blood Transfus 8(Suppl 3):s26-30

8. Baumgartner JM, Silliman CC, Moore EE, Banerjee A, McCarter MD (2009) Stored red blood cell transfusion induces regulatory T cells. J Am Coll Surg 208:110-119

9. Anniss AM, Sparrow RL (2006) Storage duration and white blood cell content of red blood cell (RBC) products increases adhesion of stored $\mathrm{RBC}$ s to endothelium under flow conditions. Transfusion 46:1561-1567

10. Sparrow RL, Healey G, Patton KA, Veale MF (2006) Red blood cell age determines the impact of storage and leukocyte burden on cell adhesion molecules, glycophorin $A$ and the release of annexin V. Transfus Apher Sci 34:15-23

11. Muszynski JA, Spinella PC, Cholette JM, Acker JP, Hall MW, Juffermans NP, Kelly DP, Blumberg N, Nicol K, Liedel J, Doctor A, Remy KE, Tucci M, Lacroix J, Norris PJ (2017) Transfusion-related immunomodulation: review of the literature and implications for pediatric critical illness. Transfusion 57:195-206

12. Atkins $D$, Best $D$, Briss PA, Eccles $M$, Falck-Ytter $Y$, Flottorp S, Guyatt GH, Harbour RT, Haugh MC, Henry D, Hill S, Jaeschke R, Leng G, Liberati A, Magrini N, Mason J, Middleton P, Mrukowicz J, 
O'Connell D, Oxman AD, Phillips B, Schunemann $\mathrm{HJ}$, Edejer T, Varonen H, Vist GE, Williams JW Jr., Zaza S (2004) Grading quality of evidence and strength of recommendations. BMJ 328:1490

13. Stang A (2011) Randomized controlled trialsan indispensible part of clinical research. Dtsch Arztebl Int 108:661-662

14. Hrobjartsson A, Emanuelsson F, Skou Thomsen AS, Hilden J, Brorson S (2014) Bias due to lack of patient blinding in clinical trials. A systematic review of trials randomizing patients to blind and nonblind sub-studies. Int J Epidemiol 43:1272-1283

15. Hrobjartsson $A$, Thomsen AS, Emanuelsson $F$ Tendal B, Hilden J, Boutron I, Ravaud P, Brorson S (2012) Observer bias in randomised clinical trials with binary outcomes: systematic review of trials with both blinded and non-blinded outcome assessors. BMJ 344:e1119

16. Sedgwick P (2015) Intention to treat analysis versus per protocol analysis of trial data. BMJ 350:h681

17. Schulz KF, Grimes DA (2005) Multiplicity in randomised trials I: endpoints and treatments. Lancet 365:1591-1595

18. Schulz KF, Grimes DA (2005) Multiplicity in randomised trials II: subgroup and interim analyses. Lancet 365:1657-1661

19. Assmann SF, Pocock SJ, Enos LE, Kasten LE (2000) Subgroup analysis and other (mis)uses of baseline data in clinical trials. Lancet 355:1064-1069

20. ISIS-Colaboration Group (1988) Randomised trial of intravenous streptokinase, oral aspirin, both, or neither among 17,187 cases of suspected acute myocardial infarction: ISIS-2. ISIS-2 (Second International Study of Infarct Survival) Collaborative Group. Lancet 2:349-360

21. Chan AW, Hrobjartsson A, Haahr MT, Gotzsche PC, Altman DG (2004) Empirical evidence for selective reporting of outcomes in randomized trials: comparison of protocols to published articles. JAMA 291:2457-2465

22. Middelburg RA, van de Watering $L M$, van der Bom JG (2010) Blood transfusions: good or bad? Confounding by indication, an underestimated problem in clinical transfusion research. Transfusion 50:1181-1183

23. Concato J, Shah N, Horwitz RI (2000) Randomized, controlled trials, observational studies, and the hierarchy of research designs. $\mathrm{N}$ Engl J Med 342:1887-1892

24. Anglemyer A, Horvath HT, Bero L (2014) Healthcare outcomes assessed with observational study designs compared with those assessed in randomized trials. Cochrane Database Syst Rev .https://doi.org/10.1002/14651858.MR000034. pub2

25. Jick H, Garcia Rodriguez LA, Perez-Gutthann S (1998) Principles of epidemiological research on adverse and beneficial drug effects. Lancet 352:1767-1770

26. Feinstein AR (1995) Meta-analysis: statistical alchemy for the 21st century. J Clin Epidemiol 48:71-79

27. Stegenga J (2011) Is meta-analysis the platinum standard of evidence? Stud Hist Philos Biol Biomed Sci 42:497-507

28. Kjaergard LL, Villumsen J, Gluud C (2001) Reported methodologic quality and discrepancies between large and small randomized trials in meta-analyses. Ann Intern Med 135:982-989

29. LeLorier J, Gregoire G, Benhaddad A, Lapierre J, Derderian F (1997) Discrepancies between meta- analyses and subsequent large randomized controlled trials. N Engl J Med 337:536-542

30. Cochrane Collaboration: Cochrane Handbook for Systematic Reviews of Interventions: The Cochrane Collaboration and John Wiley \& Sons Ltd; 2008.

31. Liberati A, Altman DG, Tetzlaff J, Mulrow C, Gotzsche PC, loannidis JP, Clarke M, Devereaux PJ, Kleijnen J, Moher D (2009) The PRISMA statement for reporting systematic reviews and meta-analyses of studies that evaluate healthcare interventions: explanation and elaboration. BMJ 339:b2700

32. Greco T, Zangrillo A, Biondi-Zoccai G, Landoni G (2013) Meta-analysis: pitfalls and hints. Heart Lung Vessel 5:219-225

33. Walker E, Hernandez AV, Kattan MW (2008) Meta-analysis: Its strengths and limitations. Cleve Clin J Med 75:431-439

34. Ioannidis JPA (2016) The Mass Production of Redundant, Misleading, and Conflicted Systematic Reviews and Meta-analyses. Milbank Q 94:485-514

35. Easterbrook PJ, Berlin JA, Gopalan R, Matthews DR (1991) Publication bias in clinical research. Lancet 337:867-872

36. Turner RM, Bird SM, Higgins JP (2013) The impact of study size on meta-analyses: examination of underpowered studies in Cochrane reviews. Plos One 8:e59202

37. Sedgwick P (2015) Meta-analyses: what is heterogeneity? BMJ 350:h1435

38. Weed DL (2000) Interpreting epidemiological evidence: how meta-analysis and causal inference methods are related. Int J Epidemiol 29:387-390

39. Hill $A B$ (1965) The environment and disease: Association or causation? Proc R Soc Med 58:295-300

40. Sparrow RL (2017) Red blood cell components: time to revisit the sources of variability. Blood Transfus 15:116-125

41. Musallam KM, Tamim HM, Richards T, Spahn DR, Rosendaal FR, Habbal A, Khreiss M, Dahdaleh FS, Khavandi K, Sfeir PM, Soweid A, Hoballah JJ, Taher AT, Jamali FR (2011) Preoperative anaemia and postoperative outcomes in non-cardiac surgery: a retrospective cohort study. Lancet 378:1396-1407

42. Richards T, Musallam KM, Nassif J, Ghazeeri G, Seoud M, Gurusamy KS, Jamali FR (2015) Impact of Preoperative Anaemia and Blood Transfusion on Postoperative Outcomes in Gynaecological Surgery. Plos One 10:e130861

43. Izaks GJ, Westendorp RG, Knook DL (1999) The definition of anemia in older persons. JAMA 281:1714-1717

44. Martinsson A, Andersson C, Andell P, Koul S, Engstrom G, Smith JG (2014) Anemia in the general population: prevalence, clinical correlates and prognostic impact. Eur J Epidemiol 29:489-498

45. Toft-Petersen AP, Torp-Pedersen C, Weinreich UM, Rasmussen BS (2016) Association between hemoglobin and prognosis in patients admitted to hospital for COPD. Int J Chron Obstruct Pulmon Dis 11:2813-2820

46. Holst LB, Petersen MW, Haase N, Perner A Wetterslev J (2015) Restrictive versus liberal transfusion strategy for red blood cell transfusion: systematic review of randomised trials with meta-analysis and trial sequential analysis. BMJ 350:h1354
47. Gregersen M (2016) Postoperative red blood cell transfusion strategy in frail anemic elderly with hip fracture. A randomized controlled trial. Dan Med J 63:B5221

48. Gregersen M, Damsgaard EM, Borris LC (2015) Blood transfusion and risk of infection in frail elderly after hip fracture surgery: the TRIFE randomized controlled trial. Eur J Orthop Surg Traumatol 25:1031-1038

49. Vandenbroucke JP (2008) Observational research, randomised trials, and two views of medical science. PLoS Med 5:e67

50. Kuss $\mathrm{O}$, Blettner M, Borgermann J (2016) Propensity Score: an Alternative Method of Analyzing Treatment Effects. Dtsch Arztebl Int 113:597-603

51. Ziemann M, Rink L, Frietsch T, Spannagl M (2017) Schuler: Immunmodulation durch Transfusion von Erythrozytenkonzentraten. Transfusionsmedizin 7:40-58

52. Glance LG, Mukamel DB, Blumberg N, Fleming FJ, Hohmann SF, Dick AW (2014) Association between surgical resident involvement and blood use in noncardiac surgery. Transfusion 54:691-700

53. Petersen ML, van der Laan MJ (2014) Causal models and learning from data: integrating causal modeling and statistical estimation. Epidemiology $25: 418-426$

54. Schisterman EF, Cole SR, Platt RW (2009) Overadjustment bias and unnecessary adjustment in epidemiologic studies. Epidemiology 20:488-495

55. Holm C, Thomsen LL, Norgaard A, LanghoffRoos J (2017) Single-dose intravenous iron infusion versus red blood cell transfusion for the treatment of severe postpartum anaemia: a randomized controlled pilot study. Vox Sang 112:122-131

56. Prick BW, Jansen AJ, Steegers EA, Hop WC, Essink-Bot ML, Uyl-de Groot CA, Akerboom $B M$, van Alphen M, Bloemenkamp KW, Boers $\mathrm{KE}$, Bremer HA, Kwee A, van Loon AJ, Metz GC, Papatsonis DN, van der Post JA, Porath MM, Rijnders RJ, Roumen FJ, Scheepers HC, Schippers DH, Schuitemaker NW, Stigter RH, Woiski MD, Mol BW, van Rhenen DJ, Duvekot JJ (2014) Transfusion policy after severe postpartum haemorrhage: a randomised non-inferiority trial. Bjog 121:1005-1014

57. Carson JL, Terrin ML, Noveck H, Sanders DW, Chaitman BR, Rhoads GG, Nemo G, Dragert K, Beaupre L, Hildebrand K, Macaulay W, Lewis C, Cook DR, Dobbin G, Zakriya KJ, Apple FS, Horney RA, Magaziner J (2011) Liberal or restrictive transfusion in high-risk patients after hip surgery. N Engl J Med 365:2453-2462

58. Carson JL, Sieber F, Cook DR, Hoover DR, Noveck $H$, Chaitman BR, Fleisher L, Beaupre L, Macaulay W, Rhoads GG, Paris B, Zagorin A, Sanders DW Zakriya KJ, Magaziner J (2015) Liberal versus restrictive blood transfusion strategy: 3-year survival and cause of death results from the FOCUS randomised controlled trial. Lancet 385:1183-1189

59. Parker MJ (2013) Randomised trial of blood transfusion versus a restrictive transfusion policy after hip fracture surgery. Injury 44:1916-1918

60. Gregersen M, Borris LC, Damsgaard EM (2015) Blood transfusion and overall quality of life after hip fracture in frail elderly patients- the transfusion requirements in frail elderly randomized controlled trial. J Am Med Dir Assoc 16:762-766 
61. Gregersen M, Borris LC, Damsgaard EM (2015) Postoperative blood transfusion strategy in frail, anemic elderly patients with hip fracture: the TRIFE randomized controlled trial. Acta Orthop 86:363-372

62. Blandfort S, Gregersen M, Borris LC, Damsgaard EM (2017) Blood transfusion strategy and risk of postoperative delirium in nursing homes residents with hip fracture. A post hoc analysis based on the TRIFE randomized controlled trial. Aging Clin Exp Res 29:459-466

63. Grover M, Talwalkar S, Casbard A, Boralessa H, Contreras M, Boralessa H, Brett S, Goldhill DR, Soni N (2006) Silent myocardial ischaemia and haemoglobin concentration: a randomized controlled trial of transfusion strategy in lower limb arthroplasty. Vox Sang 90:105-112

64. Nielsen $\mathrm{K}$, Johansson PI, Dahl B, Wagner M, Frausing B, Borglum J, Jensen K, Sturup J, Hvolris J, Rasmussen LS (2014) Perioperative transfusion threshold and ambulation after hip revision surgery - a randomized trial. BMC Anesthesiol 14:89

65. Webert KE, Cook RJ, Couban S, Carruthers J, Lee KA, Blajchman MA, Lipton JH, Brandwein JM, Heddle NM (2008) A multicenter pilot-randomized controlled trial of the feasibility of an augmented red blood cell transfusion strategy for patients treated with induction chemotherapy for acute leukemia or stem cell transplantation. Transfusion 48:81-91

66. Robitaille N, Lacroix J, Alexandrov L, Clayton L, Cortier M, Schultz KR, Bittencourt H, Duval $M$ (2013) Excess of veno-occlusive disease in a randomized clinical trial on a higher trigger for red blood cell transfusion after bone marrow transplantation: a canadian blood and marrow transplant group trial. Biol Blood Marrow Transplant 19:468-473

67. de Almeida JP, Vincent JL, Galas FR, de Almeida EP, Fukushima JT, Osawa EA, Bergamin F, Park CL, Nakamura RE, Fonseca SM, Cutait G, Alves Jl, Bazan M, Vieira S, Sandrini AC, Palomba H, Ribeiro U Jr., Crippa A, Dalloglio M, Diz Mdel P, Kalil Filho R, Auler JO Jr., Rhodes A, Hajjar LA (2015) Transfusion requirements in surgical oncology patients: a prospective, randomized controlled trial. Anesthesiology 122:29-38

68. DeZern AE, Williams K, Zahurak M, Hand W, Stephens RS, King KE, Frank SM, Ness PM (2016) Red blood cell transfusion triggers in acute leukemia: a randomized pilot study. Transfusion 56:1750-1757

69. Bergamin FS, Almeida JP, Landoni $G$, Galas F, Fukushima JT, Fominskiy E, Park CHL, Osawa EA, Diz MPE, Oliveira GQ, Franco RA, Nakamura RE, Almeida EM, Abdala E, Freire MP, Filho RK, Auler JOC Jr., Hajjar LA (2017) Liberal Versus Restrictive Transfusion Strategy in Critically III Oncologic Patients: The Transfusion Requirements in Critically III Oncologic Patients Randomized Controlled Trial. Crit Care Med 45:766-773

70. Yakymenko D, Frandsen KB, Christensen IJ, Norgaard A, Johansson PI, Daugaard G, MauSorensen M (2018) Randomised feasibility study of a more liberal haemoglobin trigger for red blood cell transfusion compared to standard practice in anaemic cancer patients treated with chemotherapy. Transfus Med 28:208-215

71. Naidech AM, Shaibani A, Garg RK, Duran IM, Liebling SM, Bassin SL, Bendok BR, Bernstein RA, Batjer HH, Alberts MJ (2010) Prospective, randomized trial of higher goal hemoglobin after subarachnoid hemorrhage. Neurocrit Care 13:313-320

72. Robertson CS, Hannay HJ, Yamal JM, Gopinath S, Goodman JC, Tilley BC, Baldwin A, Rivera LL, Saucedo-Crespo H, Ahmed O, Sadasivan S, Ponce L, Cruz-Navarro J, Shahin H, Aisiku IP, Doshi P, Valadka A, Neipert L, Waguspack JM, Rubin ML, Benoit JS, Swank P (2014) Effect of erythropoietin and transfusion threshold on neurological recovery after traumatic brain injury: a randomized clinical trial. JAMA 312:36-47

73. Leal-Noval SR, Arellano-Orden V, Munoz-Gomez M, Cayuela A, Marin-Caballos A, Rincon-Ferrari MD, Garcia-Alfaro C, Amaya-Villar R, CasadoMendez M, Dusseck R, Murillo-Cabezas F (2017) Red Blood Cell Transfusion Guided by Near Infrared Spectroscopy in Neurocritically III Patients with Moderate or Severe Anemia: A Randomized, Controlled Trial. J Neurotrauma 34:2553-2559

74. Villanueva C, Colomo A, Bosch A, Concepcion M, Hernandez-Gea V, Aracil C, Graupera I, Poca M, Alvarez-Urturi C, Gordillo J, Guarner-Argente $C$, Santalo M, Muniz E, Guarner C (2013) Transfusion strategies for acute upper gastrointestinal bleeding. N Engl J Med 368:11-21

75. Jairath V, Kahan BC, Gray A, Dore CJ, Mora A, James MW, Stanley AJ, Everett SM, Bailey AA, Dallal H, Greenaway J, Le Jeune I, Darwent M, Church N, Reckless I, Hodge R, Dyer C, Meredith S, Llewelyn C, Palmer KR, Logan RF, Travis SP, Walsh TS, Murphy MF (2015) Restrictive versus liberal blood transfusion for acute upper gastrointestinal bleeding (TRIGGER): a pragmatic, open-label, cluster randomised feasibility trial. Lancet 386:137-144

76. Shehata N, Burns LA, Nathan $H$, Hebert $P$, Hare GM, Fergusson D, Mazer CD (2012) A randomized controlled pilot study of adherence to transfusion strategies in cardiac surgery. Transfusion 52:91-99

77. Murphy GJ, Pike K, Rogers CA, Wordsworth S, Stokes EA, Angelini GD, Reeves BC (2015) Liberal or restrictive transfusion after cardiac surgery. N Engl J Med 372:997-1008

78. Mazer CD, Whitlock RP, Fergusson DA, Hall J, Belley-Cote E, Connolly K, Khanykin B, Gregory AJ, de Medicis E, McGuinness S, Royse A, Carrier FM, Young PJ, Villar JC, Grocott HP, Seeberger MD, Fremes S, Lellouche F, Syed S, Byrne K, Bagshaw SM, Hwang NC, Mehta C, Painter TW, Royse C, Verma S, Hare GMT, Cohen A, Thorpe KE, Juni P, Shehata N (2017) Restrictive or Liberal Red-Cell Transfusion for Cardiac Surgery. N Engl J Med 377:2133-2144

79. Koch CG, Sessler DI, Mascha EJ, Sabik JF 3rd, Li L, Duncan Al, Zimmerman NM, Blackstone EH (2017) A Randomized Clinical Trial of Red Blood Cell Transfusion Triggers in Cardiac Surgery. Ann Thorac Surg 104:1243-1250

80. Carson JL, Stanworth SJ, Alexander JH, Roubinian N, Fergusson DA, Triulzi DJ, Goodman SG, Rao SV, Doree C, Hebert PC (2018) Clinical trials evaluating red blood cell transfusion thresholds: An updated systematic review and with additional focus on patients with cardiovascular disease. Am Heart J 200:96-101

81. Chen QH, Wang HL, Liu L, Shao J, Yu J, Zheng RQ (2018) Effects of restrictive red blood cell transfusion on the prognoses of adult patients undergoing cardiac surgery: a meta-analysis of randomized controlled trials. Crit Care 22:142
82. Laine A, Niemi T, Schramko A (2018) Transfusion Threshold of Hemoglobin $80 \mathrm{~g} / \mathrm{L}$ Is Comparable to $100 \mathrm{~g} / \mathrm{L}$ in Terms of Bleeding in Cardiac Surgery: A Prospective Randomized Study. J Cardiothorac Vasc Anesth 32:131-139

83. Cooper HA, Rao SV, Greenberg MD, Rumsey MP, McKenzie M, Alcorn KW, Panza JA (2011) Conservative versus liberal red cell transfusion in acute myocardial infarction (the CRIT Randomized Pilot Study). Am J Cardiol 108:1108-1111

84. Carson JL, Brooks MM, Abbott JD, Chaitman B, Kelsey SF, Triulzi DJ, Srinivas V, Menegus MA, Marroquin OC, Rao SV, Noveck H, Passano E, Hardison RM, Smitherman T, Vagaonescu T, Wimmer NJ, Williams DO (2013) Liberal versus restrictive transfusion thresholds for patients with symptomatic coronary artery disease. Am Heart J 165(61):964-971.e9

85. Walsh TS, Boyd JA, Watson D, Hope D, Lewis S, Krishan A, Forbes JF, Ramsay P, Pearse R, Wallis C, Cairns C, Cole S, Wyncoll D (2013) Restrictive versus liberal transfusion strategies for older mechanically ventilated critically ill patients: a randomized pilot trial. Crit Care Med 41:2354-2363

86. Holst LB, Haase N, Wetterslev J, Wernerman J, Guttormsen AB, Karlsson S, Johansson PI, Aneman A, Vang ML, Winding R, Nebrich L, Nibro $\mathrm{HL}$, Rasmussen BS, Lauridsen JR, Nielsen JS, Oldner A, Pettila V, Cronhjort MB, Andersen LH, Pedersen UG, Reiter N, Wiis J, White JO, Russell L, Thornberg KJ, Hjortrup PB, Muller RG, Moller MH, Steensen M, Tjader I, Kilsand K, OdebergWernerman S, Sjobo B, Bundgaard H, Thyo MA, Lodahl D, Maerkedahl R, Albeck C, Illum D, Kruse M, Winkel P, Perner A (2014) Lower versus higher hemoglobin threshold for transfusion in septic shock. N Engl J Med 371:1381-1391

87. Palmieri TL, Holmes JHt AB, Peck M, Potenza B, Cochran A, King BT, Dominic W, Cartotto R, Bhavsar D, Kemalyan N, Tredget E, Stapelberg F, Mozingo D, Friedman B, Greenhalgh DG, Taylor SL, Pollock BH (2017) Transfusion Requirement in Burn Care Evaluation (TRIBE): A Multicenter Randomized Prospective Trial of Blood Transfusion in Major Burn Injury. Ann Surg 266:595-602

88. Carson JL, Stanworth SJ, Roubinian N, Fergusson DA, Triulzi D, Doree C, Hebert PC (2016) Transfusion thresholds and other strategies for guiding allogeneic red blood cell transfusion. Cochrane Database Syst Rev 10:Cd2042

89. Rohde JM, Dimcheff DE, Blumberg N, Saint S, Langa KM, Kuhn L, Hickner A, Rogers MA (2014) Health care-associated infection after red blood cell transfusion: a systematic review and metaanalysis. JAMA 311:1317-1326

90. AlFaleh $\mathrm{K}, \mathrm{Al}$-Jebreen A, Baqays A, Al-Hallali A, Bedaiwi K, Al-Balahi N, AlGhamdi A, AlKharfi T, Alzahem A (2014) Association of packed red blood cell transfusion and necrotizing enterocolitis in very low birth weight infants. J Neonatal Perinatal Med 7:193-198

91. Dame C, Sciesielski LK, Rau C, Badur CA, Buhrer C (2018) The Erythropoietin Promoter Variant rs1617640 Is Not Associated with Severe Retinopathy of Prematurity, Independent of Treatment with Erythropoietin. J Pediatr 199:256-259

92. Gephart SM (2012) Transfusion-associated necrotizing enterocolitis: evidence and uncertainty. Adv Neonatal Care 12:232-236

93. Knee D, Knoop S, Davis AT, Rawson B, DiCarlo A, Olivero R (2019) Outcomes after implementing restrictive blood transfusion criteria in extremely premature infants. J Perinatol 39:1089-1097 
94. Mohamed A, Shah PS (2012) Transfusion associated necrotizing enterocolitis: a meta-analysis of observational data. Pediatrics 129:529-540

95. Keir AK, Yang J, Harrison A, Pelausa E, Shah PS (2015) Temporal changes in blood product usage in preterm neonates born at less than 30 weeks' gestation in Canada. Transfusion 55:1340-1346

96. Keir A, Pal S, Trivella M, Lieberman L, Callum J, Shehata N, Stanworth SJ (2016) Adverse effects of red blood cell transfusions in neonates: a systematic review and meta-analysis. Transfusion 56:2773-2780

97. Haiden N, Schwindt J, Cardona F, Berger A, Klebermass K, Wald M, Kohlhauser-Vollmuth C, Jilma B, Pollak A (2006) Effects of a combined therapy of erythropoietin, iron, folate, and vitamin B12 on the transfusion requirements of extremely low birth weight infants. Pediatrics 118:2004-2013

98. Fergusson DA, Hebert P, Hogan DL, LeBel L, Rouvinez-Bouali N, Smyth JA, Sankaran K, Tinmouth A, Blajchman MA, Kovacs L, Lachance C, Lee $\mathrm{S}$, Walker CR, Hutton B, Ducharme R, Balchin K, Ramsay T, Ford JC, Kakadekar A, Ramesh K, Shapiro S (2012) Effect of fresh red blood cell transfusions on clinical outcomes in premature, very low-birth-weight infants: the ARIPI randomized trial. JAMA 308:1443-1451

99. Goodman AM, Pollack MM, Patel KM, Luban NL (2003) Pediatric red blood cell transfusions increase resource use. J Pediatr 142:123-127

100. Kneyber MC, Grotenhuis F, Berger RF, Ebels TW, Burgerhof JG, Albers MJ (2013) Transfusion of leukocyte-depleted RBCs is independently associated with increased morbidity after pediatric cardiac surgery. Pediatr Crit Care Med 14:298-305

101. Lacroix J, Hebert PC, Hutchison JS, Hume HA Tucci M, Ducruet T, Gauvin F, Collet JP, Toledano BJ, Robillard P, Joffe A, Biarent D, Meert K, Peters MJ (2007) Transfusion strategies for patients in pediatric intensive care units. N Engl J Med 356:1609-1619

102. Cholette JM, Rubenstein JS, Alfieris GM, Powers KS, Eaton M, Lerner NB (2011) Children with single-ventricle physiology do not benefit from higher hemoglobin levels post cavopulmonary connection: results of a prospective, randomized, controlled trial of a restrictive versus liberal red-cell transfusion strategy. Pediatr Crit Care Med 12:39-45

103. de Gast-Bakker DH, de Wilde RB, Hazekamp MG, Sojak V, Zwaginga JJ, Wolterbeek $R$, de Jonge $E$ (2013) Gesink-van der Veer BJ: Safety and effects of two red blood cell transfusion strategies in pediatric cardiac surgery patients: a randomized controlled trial. Intensive Care Med 39:20112019

104. Cholette JM, Swartz MF, Rubenstein J, Henrichs KF, Wang H, Powers KS, Daugherty LE, Alfieris GM, Gensini F, Blumberg N (2017) Outcomes Using a Conservative Versus Liberal Red Blood Cell Transfusion Strategy in Infants Requiring Cardiac Operation. Ann Thorac Surg 103:206214

105. Dhabangi A, Ainomugisha B, Cserti-Gazdewich C, Ddungu H, Kyeyune D, Musisi E, Opoka R, Stowell CP, Dzik WH (2015) Effect of Transfusion of Red Blood Cells With Longer vs Shorter Storage Duration on Elevated Blood Lactate Levels in Children With Severe Anemia: The TOTAL Randomized Clinical Trial. JAMA 314:2514-2523
106. Spinella PC, Tucci M, Fergusson DA, Lacroix J, Hebert PC, Leteurtre $S$, Schechtman KB, Doctor A, Berg RA, Bockelmann T, Caro JJ, Chiusolo F, Clayton L, Cholette JM, Guerra GG, Josephson CD, Menon K, Muszynski JA, Nellis ME, Sarpal A, Schafer S, Steiner ME, Turgeon AF (2019) Effect of Fresh vs Standard-issue Red Blood Cell Transfusions on Multiple Organ Dysfunction Syndrome in Critically III Pediatric Patients: A Randomized Clinical Trial. JAMA 322:2179-2190

107. Burnet M (1957) Cancer; a biological approach. I. The processes of control. Br Med J 1:779-786

108. Prehn RT, Main JM (1957) Immunity to methylcholanthrene-induced sarcomas. J Natl Cancer Inst 18:769-778

109. Jonkman-Berk BM, van den Berg JM, Ten Berge IJ, Bredius RG, Driessen GJ, Dalm VA, van Dissel $J T$, van Deuren $M$, Ellerbroek PM, van der Flier $M$, van Hagen PM, van Montfrans JM, Rutgers A Scholvinck EH, de Vries E, van Beem RT, Kuijpers TW (2015) Primary immunodeficiencies in the Netherlands: national patient data demonstrate the increased risk of malignancy. Clin Immunol 156:154-162

110. Kinlen $L J$ (1985) Incidence of cancer in rheumatoid arthritis and other disorders after immunosuppressive treatment. Am J Med 78:44-49

111. Mayor PC, Eng KH, Singel KL, Abrams SI, Odunsi K, Moysich KB, Fuleihan R, Garabedian E, Lugar P, Ochs HD, Bonilla FA, Buckley RH, Sullivan KE, Ballas ZK, Cunningham-Rundles C, Segal BH (2018) Cancer in primary immunodeficiency diseases: Cancer incidence in the United States Immune Deficiency Network Registry. J Allergy Clin Immunol 141:1028-1035

112. Opelz G, Terasaki PI (1974) Poor kidneytransplant survival in recipients with frozenblood transfusions or no transfusions. Lancet 2:696-698

113. Opelz G, Terasaki PI (1980) Dominant effect of transfusions on kidney graft survival. Transplantation 29:153-158

114. Gantt CL (1981) Red blood cells for cancer patients. Lancet 2:363

115. Bordin JO, Bardossy L, Blajchman MA (1994) Growth enhancement of established tumors by allogeneic blood transfusion in experimental animals and its amelioration by leukodepletion: the importance of the timing of the leukodepletion. Blood 84:344-348

116. Goubran H, Sheridan D, Radosevic J, Burnouf T, Seghatchian J (2017) Transfusion-related immunomodulation and cancer. Transfus Apher Sci 56:336-340

117. Madeddu C, Gramignano G, Astara G, Demontis R, Sanna E, Atzeni V, Maccio A (2018) Pathogenesis and Treatment Options of Cancer Related Anemia: Perspective for a Targeted MechanismBased Approach. Front Physiol 9:1294

118. Ludwig $\mathrm{H}$, Van Belle $\mathrm{S}$, Barrett-Lee P, Birgegard $\mathrm{G}$ Bokemeyer C, Gascon P, Kosmidis P, Krzakowski M, Nortier J, Olmi P, Schneider M, Schrijvers D (2004) The European Cancer Anaemia Survey (ECAS): a large, multinational, prospective survey defining the prevalence, incidence, and treatment of anaemia in cancer patients. Eur J Cancer 40:2293-2306

119. Edgren $G$, Bagnardi V, Bellocco R, Hjalgrim $H$, Rostgaard K, Melbye M, Reilly M, Adami HO, Hall P, Nyren $O$ (2010) Pattern of declining hemoglobin concentration before cancer diagnosis. Int J Cancer 127:1429-1436
120. Riedl R, Engels EA, Warren JL, Berghold A, Ricker W, Pfeiffer RM (2013) Blood transfusions and the subsequent risk of cancers in the United States elderly. Transfusion 53:2198-2206

121. Hjalgrim $H$, Edgren $G$, Rostgaard $K$, Reilly $M$, Tran TN, Titlestad KE, Shanwell A, Jersild C, Adami J, Wikman A, Gridley G, Wideroff L, Nyren O, Melbye $M$ (2007) Cancer incidence in blood transfusion recipients. J Natl Cancer Inst 99:1864-1874

122. Yang TO, Cairns BJ, Reeves GK, Green J, Beral V (2017) Cancer risk among 21st century blood transfusion recipients. Ann Oncol 28:393-399

123. Cerhan JR, Wallace RB, Folsom AR, Potter JD, Munger RG, Prineas RJ (1993) Transfusion history and cancer risk in older women. Ann Intern Med 119:8-15

124. Fujino $Y$, Tamakoshi A, Hoshiyama Y, Mikami H, Okamoto N, Ohno Y, Yoshimura T (2004) Prospective study of transfusion history and thyroid cancer incidence among females in Japan. Int J Cancer 112:722-725

125. Chang CM, Quinlan SC, Warren JL, Engels EA (2010) Blood transfusions and the subsequent risk of hematologic malignancies. Transfusion 50:2249-2257

126. Blomberg J, Moller $\mathrm{T}$, Olsson $\mathrm{H}$, Anderson $\mathrm{H}$, Jonsson M (1993) Cancer morbidity in blood recipients-results of a cohort study. Eur J Cancer 29a:2101-2105

127. Inoue $Y$, Wada $Y$, Motohashi $Y$, Koizumi A (2010) History of blood transfusion before 1990 is associated with increased risk for cancer mortality independently of liver disease: a prospective long-term follow-up study. Environ Health Prev Med 15:180-187

128. Castillo JJ, Dalia S, Pascual SK (2010) Association between red blood cell transfusions and development of non-Hodgkin lymphoma: a meta-analysis of observational studies. Blood 116:2897-2907

129. Morton LM, Slager SL, Cerhan JR, Wang SS, Vajdic CM, Skibola CF, Bracci PM, de Sanjose S, Smedby KE, Chiu BC, Zhang Y, Mbulaiteye SM, Monnereau A, Turner JJ, Clavel J, Adami $\mathrm{HO}$, Chang ET, Glimelius B, Hjalgrim H, Melbye M, Crosignani P, di Lollo S, Miligi L, Nanni O, Ramazzotti V, Rodella S, Costantini AS, Stagnaro E, Tumino R, Vindigni C, Vineis $P$, Becker $N$, Benavente $Y$, Boffetta $P$, Brennan $P$, Cocco $P$ Foretova L, Maynadie M, Nieters A, Staines A, Colt JS, Cozen W, Davis S, de Roos AJ, Hartge P, Rothman N, Severson RK, Holly EA, Call TG, Feldman AL, Habermann TM, Liebow M, Blair A Cantor KP, Kane EV, Lightfoot T, Roman E, Smith A, Brooks-Wilson A, Connors JM, Gascoyne RD, Spinelli JJ, Armstrong BK, Kricker A, Holford TR, Lan Q, Zheng T, Orsi L, Dal Maso L, Franceschi $S$, La Vecchia C, Negri E, Serraino D, Bernstein L, Levine A, Friedberg JW, Kelly JL, Berndt SI, Birmann BM, Clarke CA, Flowers CR, Foran JM, Kadin ME, Paltiel O, Weisenburger DD, Linet MS, Sampson JN (2014) Etiologic heterogeneity among non-Hodgkin lymphoma subtypes: the InterLymph Non-Hodgkin Lymphoma Subtypes Project. J Natl Cancer Inst Monogr 48:130-144

130. Memon A, Doll R (1994) A search for unknown blood-borne oncogenic viruses. Int J Cancer 58:366-368

131. Anderson $\mathrm{H}$, Brandt $\mathrm{L}$, Ericson $\mathrm{A}$, Olsson $\mathrm{H}$ Moller T (1998) Blood transfusion at delivery and risk of subsequent malignant lymphoma in the mother. Vox Sang 75:145-148 
132. Skanberg J, Frisk B (1999) Blood transfusion does not influence the development of malignant tumours. Eur J Surg 165:528-534

133. Waymack JP, Chance WT (1988) Effect of blood transfusions on immune function: IV. Effect on tumor growth. J Surg Oncol 39:159-164

134. Busch OR, Hop WC, Hoynck van Papendrecht MA, Marquet RL, Jeekel J (1993) Blood transfusions and prognosis in colorectal cancer. N Engl J Med 328:1372-1376

135. Heiss MM, Mempel W, Delanoff C, Jauch KW, Gabka C, Mempel M, Dieterich HJ, Eissner HJ, Schildberg FW (1994) Blood transfusionmodulated tumor recurrence: first results of a randomized study of autologous versus allogeneic blood transfusion in colorectal cancer surgery. J Clin Oncol 12:1859-1867

136. Harlaar JJ, Gosselink MP, Hop WC, Lange JF, Busch OR, Jeekel $\mathrm{H}$ : Blood transfusions and prognosis in colorectal cancer: long-term results of a randomized controlled trial. Ann Surg 2012; 256: 681-686; discussion 686-687.

137. Cao L, Selby LV, Hu X, Zhang Y, Janjigian YY, Tang L, Coit DG, Brennan MF, Strong VE (2016) Risk factors for recurrence in T1-2N0 gastric cancer in the United States and China. J Surg Oncol 113:745-749

138. Donohue JH, Williams S, Cha S, Windschitl HE, Witzig TE, Nelson H, Fitzgibbons RJ Jr., Wieand HS, Moertel CG (1995) Perioperative blood transfusions do not affect disease recurrence of patients undergoing curative resection of colorectal carcinoma: a Mayo/North Central Cancer Treatment Group study. J Clin Oncol 13:1671-1678

139. Edna TH, Bjerkeset $T$ (1998) Perioperative blood transfusions reduce long-term survival following surgery for colorectal cancer. Dis Colon Rectum 41:451-459

140. Jagoditsch M, Pozgainer P, Klingler A, Tschmelitsch J (2006) Impact of blood transfusions on recurrence and survival after rectal cancer surgery. Dis Colon Rectum 49:1116-1130

141. Talukder Y, Stillwell AP, Siu SK, Ho YH (2014) Comparing survival and recurrence in curative stage I to III colorectal cancer in transfused and nontransfused patients. Int Surg 99:8-16

142. Warschkow R, Guller U, Koberle D, Muller SA, Steffen T, Thurnheer M, Schmied BM, Tarantino I (2014) Perioperative blood transfusions do not impact overall and disease-free survival after curative rectal cancer resection: a propensity score analysis. Ann Surg 259:131-138

143. Mörner ME, Edgren G, Martling A, Gunnarsson U, Egenvall M (2017) Preoperative anaemia and perioperative red blood cell transfusion as prognostic factors for recurrence and mortality in colorectal cancer-a Swedish cohort study. Int J Colorectal Dis 32:223-232

144. Amri R, Dinaux AM, Leijssen LGJ, Kunitake $H$, Bordeianou LG, Berger DL (2017) Do packed red blood cell transfusions really worsen oncologic outcomes in colon cancer? Surgery 162:586-591

145. Wu HL, Tai YH, Lin SP, Chan MY, Chen HH, Chang KY (2018) The Impact of Blood Transfusion on Recurrence and Mortality Following Colorectal Cancer Resection: A Propensity Score Analysis of 4,030 Patients. Sci Rep 8:13345

146. Choi GH, Kim DH, Choi SB, Kang CM, Kim KS, Choi JS, Lee WJ, Han KH, Chon CY, Kim BR (2009) The preoperative positivity for serum hepatitis $B$ e antigen did not affect overall survival after curative resection of hepatitis $B$ virus-related he- patocellular carcinoma. J Gastroenterol Hepatol 24:391-398

147. Wang CC, lyer SG, Low JK, Lin CY, Wang SH, Lu SN, Chen CL (2009) Perioperative factors affecting long-term outcomes of 473 consecutive patients undergoing hepatectomy for hepatocellular carcinoma. Ann Surg Oncol 16:1832-1842

148. Harada N, Shirabe K, Maeda T, Kayashima H, Ishida T, Maehara Y (2015) Blood transfusion is associated with recurrence of hepatocellular carcinoma after hepatectomy in Child-Pugh class A patients. World J Surg 39:1044-1051

149. Yang T, Lu JH, Lau WY, Zhang TY, Zhang H, Shen YN, Alshebeeb K, Wu MC, Schwartz M, Shen F (2016) Perioperative blood transfusion does not influence recurrence-free and overall survivals after curative resection for hepatocellular carcinoma: A Propensity Score Matching Analysis. J Hepatol 64:583-593

150. Linder BJ, Frank I, Cheville JC, Tollefson MK, Thompson RH, Tarrell RF, Thapa P, Boorjian SA (2013) The impact of perioperative blood transfusion on cancer recurrence and survival following radical cystectomy. Eur Urol 63:839-845

151. Abel EJ, Linder BJ, Bauman TM, Bauer RM, Thompson RH, Thapa P, Devon ON, Tarrell RF, Frank I, Jarrard DF, Downs TM, Boorjian SA (2014) Perioperative blood transfusion and radical cystectomy: does timing of transfusion affect bladder cancer mortality? Eur Urol 66:11391147

152. Kluth LA, Xylinas E, Rieken $M$, El Ghouayel M, Sun M, Karakiewicz PI, Lotan Y, Chun FK, Boorjian SA, Lee RK, Briganti A, Roupret M, Fisch M, Scherr DS, Shariat SF (2014) Impact of peri-operative blood transfusion on the outcomes of patients undergoing radical cystectomy for urothelial carcinoma of the bladder. BJU Int 113:393-398

153. Moschini M, Dell' Oglio P, Capogrosso P, Cucchiara V, Luzzago S, Gandaglia G, Zattoni F, Brigant A, Damiano R, Montorsi F, Salonia A, Colombo R (2015) Effect of Allogeneic Intraoperative Blood Transfusion on Survival in Patients Treated With Radical Cystectomy for Nonmetastatic Bladder Cancer: Results From a Single High-Volume Institution. Clin Genitourin Cancer 13:562-567

154. Vetterlein MW, Gild P, Kluth LA, Seisen T, Gierth $M$, Fritsche HM, Burger M, Protzel C, Hakenberg OW, von Landenberg N, Roghmann F, Noldus J, Nuhn P, Pycha A, Rink M, Chun FK, May M, Fisch M, Aziz A (2018) Peri-operative allogeneic blood transfusion does not adversely affect oncological outcomes after radical cystectomy for urinary bladder cancer: a propensity scoreweighted European multicentre study. BJU Int 121:101-110

155. Uccella S, Ghezzi F, Cromi A, Bogani G, Formenti G, Donadello N, Serati M, Bolis P (2013) Perioperative allogenic blood transfusions and the risk of endometrial cancer recurrence. Arch Gynecol Obstet 287:1009-1016

156. Lopez-Aguiar AG, Ethun CG, McInnis MR, Pawlik TM, Poultsides $G$, Tran T, Idrees K, Isom CA, Fields RC, Krasnick BA, Weber SM, Salem A, Martin RCG, Scoggins CR, Shen P, Mogal HD, Schmidt C, Beal EW, Hatzaras I, Shenoy R, Cardona K, Maithel SK (2018) Association of perioperative transfusion with survival and recurrence after resection of gallbladder cancer: A 10-institution study from the US Extrahepatic Biliary Malignancy Consortium. J Surg Oncol 117:1638-1647

157. Abu-Ghanem Y, Dotan Z, Zilberman DE, Kaver I, Ramon J (2019) Intraoperative but not postope- rative blood transfusion adversely affect cancer recurrence and survival following nephrectomy for renal cell carcinoma. Sci Rep 9:1160

158. Linder BJ, Boorjian SA (2013) Reply to Samuel Bishara and Jim Adshead's letter to the editor re: Brian J. Linder, Igor Frank, John C. Cheville, et al. The impact of perioperative blood transfusion on cancer recurrence and survival following radical cystectomy. Eur Urol 63:839-845. Eur Urol 64:e49-50

159. Ito $Y, K$ Kanda $M$, Ito $S$, Mochizuki $Y$, Teramoto $\mathrm{H}$, Ishigure $\mathrm{K}$, Murai T, Asada T, Ishiyama A, Matsushita H, Tanaka C, Kobayashi D, Fujiwara M, Murotani K, Kodera Y (2019) Intraoperative Blood Loss is Associated with Shortened Postoperative Survival of Patients with Stage II/ III Gastric Cancer: Analysis of a Multi-institutional Dataset. World J Surg 43:870-877 